Understanding the Perpetrator's Experience: Shame, Guilt, and Forgiveness

by

\title{
Elisabeth Xie
}

\begin{abstract}
A thesis submitted to the
Faculty of Graduate and Postdoctoral Affairs

in partial fulfillment of the requirements for the degree of
\end{abstract}

\author{
Master of Arts \\ in \\ Psychology \\ Carleton University \\ Ottawa, Canada
}

(C) 2020

Elisabeth Xie 


\begin{abstract}
Research on transgressions has focused almost exclusively on the experience of the victim. Extrapolating from the attributional theory of motivation and emotion, this research aimed to gain a better understanding of how individuals make sense of a perpetrator's experience following transgressions. In three studies (combined $\mathrm{N}=288 ; 73.3 \%$ female; Mage $=21.3$ ) undergraduate students read hypothetical transgressions and assessed perceived likelihood of shame, guilt, forgiveness seeking, and self-forgiveness from the actor in each scenario. Results suggest that people sometimes do make a distinction between shame and guilt and that causal attributions and whether victims were involved in the transgression may aid people in making this distinction. Results also suggest that causal attributions, the presence of other victims, and perceived emotions may influence perceptions about forgiveness. These findings may allow for a more in-depth understanding of the psychology of transgressions and may have implications for law and conflict resolution.
\end{abstract}

Keywords: Shame, Guilt, Forgiveness, Perpetrator, Transgression 


\section{Acknowledgments}

First and foremost, thank you to my supervisor, Dr. Chris Davis, for sharing your passion for science and tremendous knowledge in psychology. You have helped me to become a more thoughtful and motivated researcher. It is a privilege to have had you as my mentor. Thank you to the other incredible researchers that I have had the honour of working with during my time as a Masters student. Dr. Rachel Burns, Dr. Susan Boon, and Dr. Michael Wohl, you have all taught me invaluable skills and have contributed immensely to my development. For that, I am sincerely thankful.

This research was funded by the Social Sciences and Humanities Research Council, the Government of Ontario, and Carleton University. Thank you to these funding agencies for providing me with the financial support necessary to dedicate my time and attention to my research projects. Thank you to the Department of Psychology for helping to provide me with incredible opportunities.

I would also like to express my sincerest gratitude to my family and my friends, both old and new. Your continuous support and patience propel me forward. Thank you for listening to my ideas and giving me advice. To my labmates and the wonderful friends who I have had the pleasure of meeting during my Masters program, this degree would not have been the same without you all.

Thank you to my partner, Connor, for your constant love, support, and encouragement. Thank you for celebrating my accomplishments and always believing in me when things get tough. You inspire me and help me dream bigger each and every day. 


\section{Table of Contents}

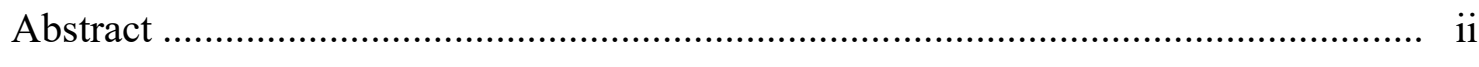

Acknowledgments ........................................................................................

Table of Contents ........................................................................................ iv

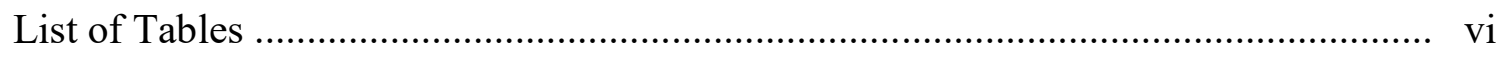

List of Figures ............................................................................................ vii

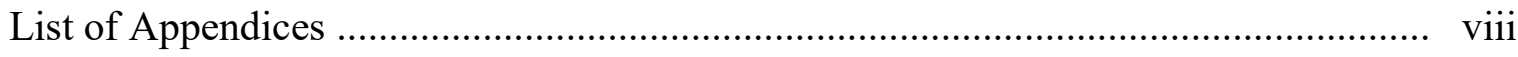

Introduction .................................................................................................. 1

Weiner's attributional theory of motivation and emotion ............................ 2

The role of causal attributions on pereceptions of shame and guilt ............... 3

The influence of perceived emotions on perceived behavioural response ........ 6

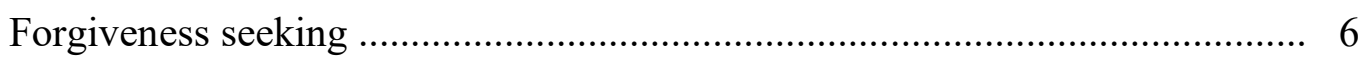

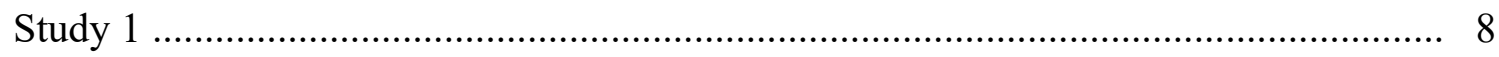

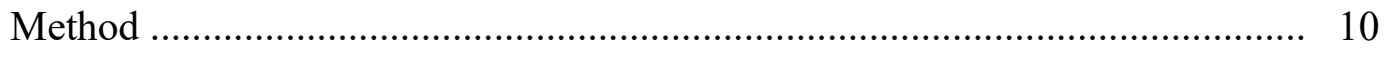

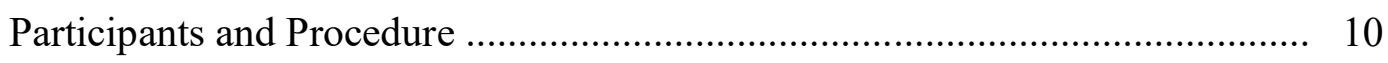

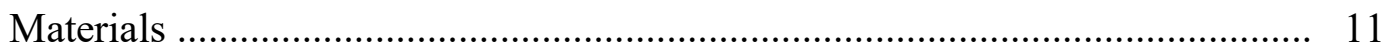

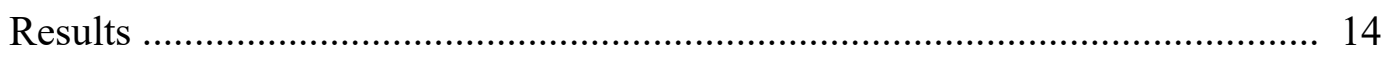

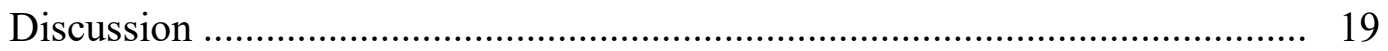

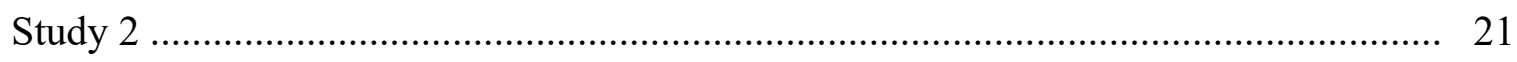

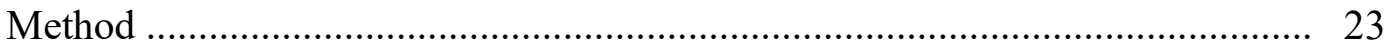

Participants and Procedure ............................................................... 23

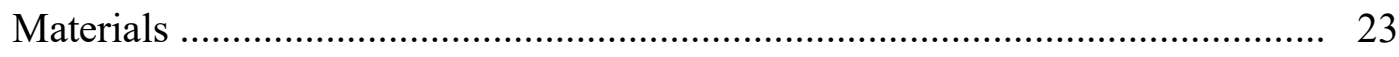

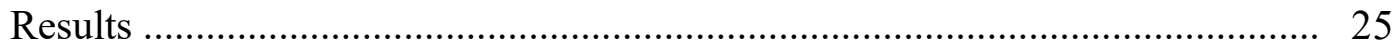




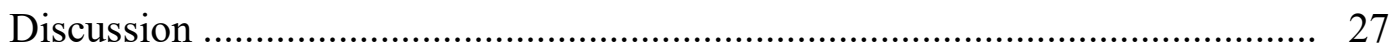

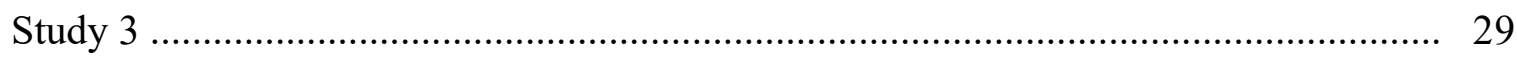

Method …..................................................................................... 31

Participants and Procedure ..................................................................... 31

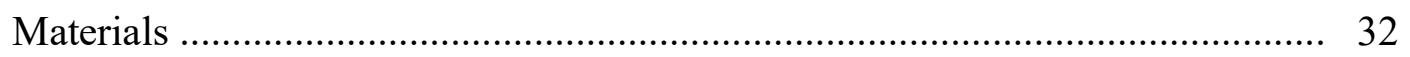

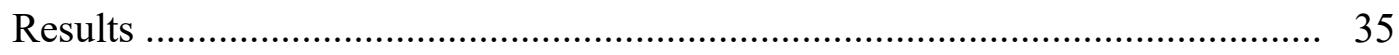

Discussion ...................................................................................... 42

General Discussion .................................................................................... 48

Shame and guilt distinction ............................................................ 48

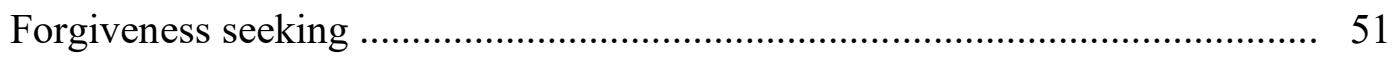

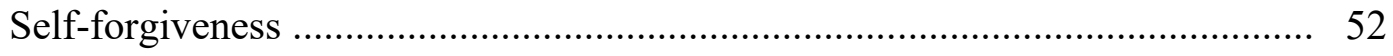

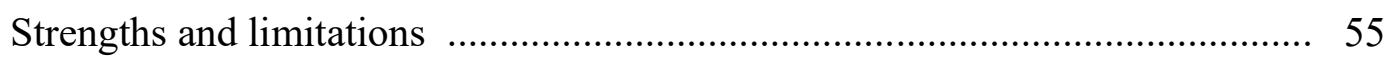

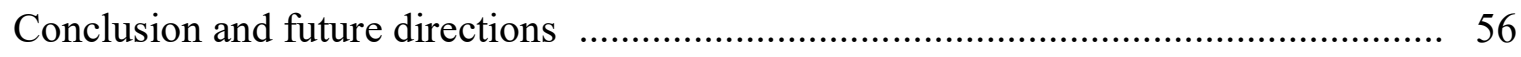

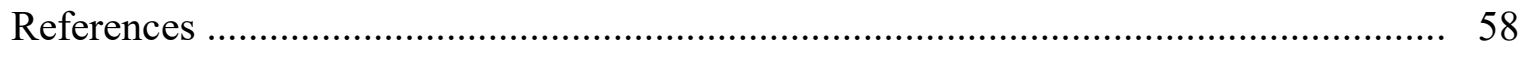




\section{List of Tables}

Table 1. Assessments of primary emotions in scenarios ....................................... 15

Table 2. Bivariate correlations between emotions ................................................. 16

Table 3. Bivariate correlations between items assessing shame and guilt ................. 36

Table 4. Bivariate correlations between emotions and forgiveness (interpersonal) .... 42

Table 5. Bivariate correlations between emotions and forgiveness (intrapersonal) ..... 42 


\section{List of Figures}

Figure 1. Interaction (emotion x type) in unstable-controllable scenarios (Study 1) ... 17

Figure 2. Interaction (emotion x type) in stable-uncontrollable scenarios (Study 1) ... 18

Figure 3. Interaction (emotion x type) in unstable-controllable scenarios (Study 2) ... 26

Figure 4. Interaction (emotion x type) in stable-uncontrollable scenarios (Study 2) ... 27

Figure 5. Interaction (emotion x type) in unstable-controllable scenarios (Study 3) ... 37

Figure 6. Interaction (emotion x type) in stable-uncontrollable scenarios (Study 3) ... 38

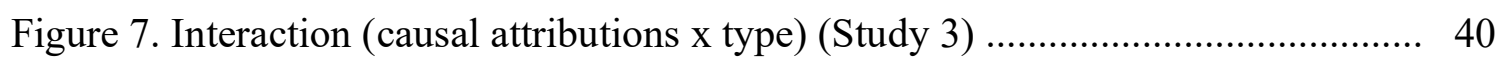




\section{List of Appendices}

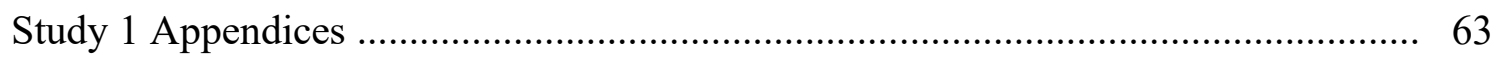

Appendix A: Recruitment Notice .......................................................... 63

Appendix B: Informed Consent ................................................... 64

Appendix C: Survey Materials ............................................................ 66

Appendix D: Debriefing …......................................................................... 77

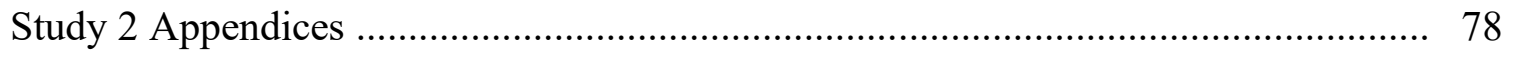

Appendix A: Recruitment Notice .......................................................... 78

Appendix B: Informed Consent .......................................................... 79

Appendix C: Survey Materials .......................................................... 81

Appendix D: Debriefing ................................................................ 87

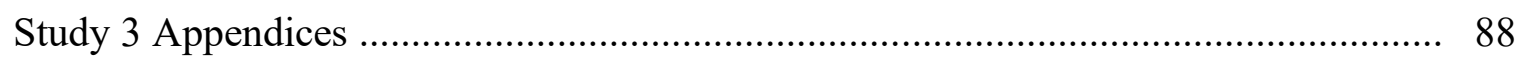

Appendix A: Recruitment Notice ................................................... 88

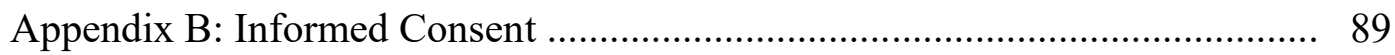

Appendix C: Survey Materials ........................................................ 91

Appendix D: Debriefing .................................................................. 98 
Understanding the Perpetrator's Experience: Shame, Guilt, and Forgiveness

The title character in the film, "The Joker", grows from a bullied, isolated child into a criminal mastermind who brutalizes others who he believes have judged or wronged him. Whereas viewers naturally sympathize with his victims, he challenges viewers to consider the crimes from the perpetrator's perspective: "Nobody thinks what it's like to be the other guy" (Philips, Cooper, \& Tillinger, 2019). This quote captures the current state of knowledge in the psychology of transgressions. Research on transgressions has focused almost exclusively on the experience and perspective of the victim. However, when there is a victim, there is almost always an involved perpetrator - whether the nature of the transgression is interpersonal (in which the victim and perpetrator are different individuals), or intrapersonal (in which the victim is also the perpetrator). As social beings in a world where transgressions are inevitable, it is likely that all of us will at some point find ourselves in both roles - that of the victim as well as that of the perpetrator. Thus, the experience of harming others is no less universal than being on the receiving end of harm. In order to gain a fuller understanding of the psychology of transgressions, it is crucial to also consider the perpetrator's experience following a wrongdoing.

The current thesis examined the ways in which observers, who are not directly affected by a wrongdoing but do have some information about the situation, think about how perpetrators feel after causing unintentional harm to themselves, and in some cases, others. This research used the attributional theory of motivation and emotion (Weiner, 1985) to explore how causal attributions for negative outcomes relate to people's perceptions of subsequent emotional responses and forgiveness seeking on the part of perpetrators of transgressions. Specifically, this thesis explored how individuals distinguish between a perpetrator's feelings of shame and guilt, 
and whether this has implications for perceived likelihood of seeking forgiveness from victims and self-forgivenss.

\section{Weiner's attributional theory of motivation and emotion}

The attributional theory of motivation and emotion proposed by Weiner (1985) is one approach to examining the antecedents of emotions. This model suggests that unique combinations of causality dimensions elicit different emotional experiences, which in turn motivate behaviour. According to Weiner (1985), there are three distinct causal dimensions that have implications for emotional responses. The first dimension is the locus of causality, which refers to whether the cause of an outcome (e.g., performance on a test, a misdemeanor, or a crime) is attributable to internal or external sources. Recognizing that internal causes can fluctuate or remain quite constant, Weiner et al. (1971) introduced the dimension of stability. Stability refers to whether an outcome is attributable to temporary and variable factors like effort, mood, or fatigue or attributable to constant and enduring factors like one's aptitude or personality traits. The third established dimension is controllability (Weiner, 1979), which refers to whether an outcome is attributable to factors that people can choose to alter like effort, or willingness or attributable to factors that people do not have influence over like a genetic disorder. The controllability dimension was established in response to Rosenbaum's (1972) recognition that internal/stable and internal/unstable attributions can be further distinguished. For instance, when examining internal and unstable causes, effort, mood, and fatigue differ in that effort can typically be controlled, whereas mood and the onset of fatigue is typically subject to less volitional control. When examining internal and stable causes, some trait-like qualities, such as laziness or level of tolerance, are perceived as more controllable than academic or artistic aptitude. 


\section{The role of causal attributions on pereceptions of shame and guilt}

The attributional theory of motivation and emotion involves a cognition-emotion process, which is thought to influence one's emotions following an event (Weiner, 1985). This process suggests that outcome evaluation first leads to an initial outcome-related emotion (e.g., happiness when the outcome is success and frustration or sadness when the outcome is failure).

Subsequently, one seeks to understand the causes that produced the outcome. These attributions modify the initial emotional response. The locus of causality influences self-related (selfreflective) emotions, with internal ascriptions having a greater influence on self-related emotions than external ascriptions. For instance, if an individual loses her house due to a tornado (external cause), this has less of an influence on her feelings about herself, compared to losing her house due to poor money management (internal cause). Two self-related emotions to which Weiner (1985) has assigned unique causal attributions are shame and guilt. Shame and guilt are referred to as moral emotions as they are negative, painful, and tense self-evaluations that foster moral conduct (Tangney, 1995; Wicker et al., 1983). Weiner suggested that shame and guilt both arise from internal attributions following negative outcomes; one should not feel shame or guilt if the cause is ascribed to external sources. This is supported by a number of studies (Hudley, 1992; Kuppens, Van Mechlen, Smits, \& De Boek, 2003; Tracy \& Robins, 2006).

Weiner suggested that shame and guilt are distinguished by the controllability dimension. According to his model, shame arises from internal, uncontrollable attributions (e.g., lack of ability), whereas guilt arises from internal, controllable attributions (e.g., lack of effort). There is some support for the controllability-shame/guilt association. For students who considered their exam a failure, feelings of shame were more highly correlated with poor ability attributions compared to poor effort attributions (Covington \& Omelich, 1984). The opposite was true for 
feelings of guilt (Covington \& Omelich, 1984). Furthermore, participants who read hypothetical scenarios expected that they would experience more guilt when effort was low compared to high (Jagacinski \& Nicholls, 1984). Weiner (1985) did not explicitly mention his predictions about how stability should relate to shame and guilt. However, his provided examples (i.e., lack of ability and lack of effort) may shine light on the stability dimension. Weiner has used ability as an example of an internal-stable-uncontrollable attribution, suggesting it is the combination of these attributions that elicit shame, whereas he has used lack of effort as an example of an internal-unstable-controllable attribution, suggesting this combination of attributions elicits guilt.

Weiner's (1985) proposed distinction between guilt and shame has received more recent empirical support. Tracy and Robins (2006) tested unique appraisal antecedents of shame and guilt. They found that internal attributions lead to self-conscious emotions, such that when individuals blame themselves for failure, rather than external sources, they experience a greater degree of self-conscious emotions (e.g., shame and guilt). Furthermore, when individuals attributed their poor grades to insufficient effort (internal, unstable, and controllable cause) they tended to experience guilt, whereas when individuals attributed their poor grades to lack of ability (internal, stable, and uncontrollable cause), they tended to experience shame. Tracy and Robins proceeded to present participants with a series of vignettes in which they manipulated locus, stability, and controllability. The same findings held true when Tracy and Robins manipulated controllability and stability dimensions - internal-stable attributions led to greater shame whereas internal-unstable attributions led to greater guilt. Furthermore, internalcontrollable attributions led to greater shame whereas internal-uncontrollable attributions led to greater guilt. The controllability manipulation (i.e., you did badly on the exam because you "didn't bother to study" vs. "you have never had much natural talent") had a larger effect on the 
distinction between shame and guilt than did the stability dimension. These findings suggest that the ways in which a perpetrator appraises his or her transgression might determine the subsequent moral affect.

Other researchers have suggested alternative perspectives on the distinction between shame and guilt. Lewis (1971) has argued that shame arises from negative evaluations of the self ( $I$ was late for work), whereas guilt arises from negative evaluations of specific behaviours (I was late for work). Niedenthal, Tangney, and Gavanski (1994) have found that shame and guilt involve distinct counterfactual thoughts that are consistent with Lewis' (1971) self versus behaviour perspective. When participants were asked to recall experiences of shame or were induced to feel shame, they were more likely to mentally undo aspects of the self (e.g., "if only I weren't so self-centered") whereas when participants were asked to recall experiences of guilt or were induced to feel guilt, they were more likely to mentally undo aspects of the behaviour (e.g., "if only I turned down the AC"). Furthermore, when directed to make counterfactuals about the self (if only I were (not)), participants reported more shame, whereas when directed to make counterfactual about the behaviour (if only I had (not)), participants reported greater levels of guilt.

Lewis' (1971) self-behaviour distinction seems to share some similarities with Weiner's causal attribution theory. Whereas Weiner (1985) suggests that guilt emerges from attributions for negative outcomes that are internal and controllable (hence, more focus on specific action, i.e., "I was late for my meeting because I chose to walk this morning; I could have controlled that behaviour"), he suggests that shame emerges from internal and uncontrollable negative outcomes (hence, more focus on the self, i.e., "I was late for my meeting because $I$ cannot manage to wake up when my alarm goes off; it must be me"). 


\section{The influence of perceived emotions on perceived behavioural response}

Weiner's attributional theory of motivation and emotion (1985) presumes that the unique affective responses that result from causal attributions determine subsequent motivated behaviours. It is reasonable to assume that individuals will desire to alleviate shame and guilt as these emotions are painful, agitating, and depressing (Wicker, Payne, \& Morgan, 1983). Shame and guilt promote different patterns of behaviour, with shame leading to withdrawal, avoidance, inhibition and guilt promoting more approach behaviour and motivating the desire to apologize and confess (Hoffman, 1982; Tangney, 1995; Wicker et al., 1983). Others have also adopted this perspective. For instance, Tracy and Robins (2006) suggest that the guilt one feels may motivate efforts to confess, make amends, and better one's behaviour, whereas the shame one feels may motivate escape and avoidance of future attempts in situations that might reveal a stable flaw. Although there seems to be some agreement among researchers that shame and guilt promote different behavioural responses, little research has explored when people attempt to seek remedial outcomes, such as forgiveness.

\section{Forgiveness Seeking}

One way that individuals might attempt to alleviate their distressing moral affect is through the seeking of forgiveness from those whom they have hurt. Similar to the research on transgressions, the forgiveness literature has primarily focused on the forgiveness process from the perspective of the victim, such as the predictors and outcomes of granting forgiveness to those who have committed the wrong. Individuals are more likely to forgive the perpetrator when they perceive the perpetrator to be less responsible for the action, when they have a greater level of empathy and relational commitment, when the victim engages in less rumination, and when the perpetrator demonstrates remorse and provides an apology (McCullough et al., 1998; 
Ysseldyk \& Wohl, 2012). Demonstrating remorse promotes forgiveness as it signals that the offense will not happen again (Gold \& Weiner, 2000), whereas apologies increase the level of empathy a victim has for the transgressor (McCullough et al., 1998). Furthermore, victims are more willing to forgive the perpetrator when they perceive the transgression to be temporally farther away (Wohl \& McGrath, 2007). Although there is a good understanding of what makes a victim more likely to grant forgiveness, whether one does so is ultimately out of the control of the perpetrator. A perpetrator can only control the extent to which he or she seeks forgiveness from the victim.

Seeking forgiveness involves any implicit or explicit attempt to communicate remorse or restitution following an acknowledged offense (Riek, 2010). Researchers have suggested that an inability or unwillingness to seek forgiveness can have negative consequences for a perpetrator's reputation and relationships, leading to problems such as social isolation (Sandage, Worthington, Hight, \& Berry, 2000). Given the importance of forgiveness seeking, researchers have recently begun exploring the ways in which individuals do so, as well as the predictors of forgiveness seeking, in order to better understand how and when forgiveness seeking can occur. People can demonstrate a desire for forgiveness through a number of ways such as making reparations, explicit apologies or changing one's behaviour towards the victim (Riek, 2010). Individuals report more forgiveness-seeking behaviours when they perceive the transgression to have been more severe, when they feel more responsible, experience more rumination, and are more committed to the relationship with the victim (Riek, 2014). Guilt is also a primary predictor of seeking forgiveness and a mediator between the aforementioned situational factors and forgiveness seeking (Riek, 2014). These findings are consistent with earlier research on apologies suggesting that when individuals feel a greater level of guilt for making others angry, 
they are more likely to offer an apology to the victim compared to individuals who did not feel as much guilt (Baumeister, Stillwell, \& Heatherton, 1995). However, when guilt is accounted for, shame appears to be unrelated to forgiveness-seeking behaviours (Riek, 2014).

Considering the implications of seeking forgiveness for both the perpetrator and the victim, the current study aims to explore whether people believe that guilt and shame promote forgiveness-seeking behaviours following negative outcomes. Given that the self-focus associated with shame is likely to pull attention and empathy away from distressed others and that guilt motivates empathy for the victims and acts as a mechanism for relationship maintenance and repair (Schmader \& Lickel, 2006; Tangney, 1995), it was predicted that presumed guilt inducing attributions, more than presumed shame inducing attributions, would be associated with greater perceived likelihood of forgiveness seeking. It was also predicted that perceptions of guilt, more than perceptions of shame, would be positively associated with perceived likelihood of forgiveness seeking.

\section{Study 1}

One of the main purposes of this thesis was to assess how shame and guilt inducing causal attributions and shame and guilt relate to forgiveness seeking. Thus, the goal of study 1 was to determine if people's perceptions of a perpetrator's experience following a transgression were consistent with the attributional theory of motivation and emotion outlined by Weiner (1985). Specifically, study 1 was designed to test whether the unique combination of causal antecedents of shame and guilt extend to perceptions of a perpetrator's experience following wrongdoings. Furthermore, I sought to examine whether the associations between shame, guilt, and forgiveness seeking behaviours outlined by Riek (2014) extend to the perceptions of a perpetrator's likelihood of seeking forgiveness from others following the commitment of a 
transgression. This study tested whether varying the causal dimensions of controllability and stability results in differences in perceived shame and guilt and differences in perceived likelihood of forgiveness seeking. This study goes beyond the work of Weiner (1985) by assessing the extent to which the perceived emotional response differed as a function of whether the transgression was interpersonal (someone other than the actor was the victim of the transgression) or intrapersonal (the protagonist was the victim). Extrapolating from Weiner's shame-guilt distinction and existing theories of the behavioural outcomes of shame and guilt, this research aimed to explore the ways in which individuals make sense of a perpetrators' response following a negative outcome or the commitment of harm to oneself and/or others.

One concern with studying the distinct attributional antecedents of shame and guilt is that people may consider shame and guilt to be synonymous. To assess whether individuals make the distinction between these emotional responses in the way that Weiner's theory suggests they should, half of the participants were presented scenarios and asked to select which of four emotional responses (guilt, shame, sadness, anxiety) would be most likely to be felt by the actor (i.e., a multiple choice format; the latter two emotions were included as distractors). The remaining participants were asked to rate the extent to which the same actor would feel each of the same four emotions (i.e., a continuous response method). I chose to test two response options to determine whether participants were distinguishing between shame and guilt in the same ways in both versions. It was predicted that some scenarios would elicit at least some degree of both shame and guilt, and thus, when given the option in the continuous version, participants might choose both emotions to the same extent. Therefore, I wanted participants to think about the "primary" emotion in order to determine whether they can make a distinction between shame and 
guilt as well as test whether the degree of shame and guilt might differ (through use of the Likert scale).

Based on Weiner's theory and the research conducted by Robins and Tracy (2006), I first hypothesized that when a perpetrator's behaviour was unstable (temporary) and controllable, participants in the multiple choice version would be more likely to perceive that the perpetrator would feel guilt than shame. For those in the emotion rating condition, I hypothesized that in this situation participants would perceive that the perpetrator would feel more guilt than shame (Hypothesis 1). However, I hypothesized that when the perpetrator's behaviour was portrayed as stable (enduring) and uncontrollable, participants would perceive that the perpetrator would feel more shame than guilt (and if in the multiple choice version, be more likely to indicate shame than guilt as the primary emotional response) (Hypothesis 2).

Third, given that guilt appears to be more linked to relationship repair tactics, and is thus viewed as a more adaptive response to interpersonal transgressions compared to shame (Tangney, 1995), I hypothesized that, within interpersonal transgressions, people would perceive a greater likelihood of forgiveness seeking following guilt inducing attributions (unstablecontrollable) compared to shame inducing attributions (stable-uncontrollable) (Hypothesis 3). I also predicted that people would perceive a greater likelihood of forgiveness seeking when they also perceived a greater level of guilt compared to shame from the perpetrator; guilt would predict forgiveness seeking over and above shame but shame would not predict forgiveness seeking over and above guilt (Hypothesis 4).

\section{Method}

\section{Participants and procedure.}


Undergraduate students $\left(N=79, M_{\text {age }}=23.66, S D=6.27,69.60 \%\right.$ female $)$ from Carleton University read a series of hypothetical scenarios describing situations in which a transgression has occurred. The scenarios varied the extent to which the cause of the transgression appeared to be stable or unstable, controllable or uncontrollable, and whether the primary victim was the transgressor (intrapersonal) or another person(s) (interpersonal). Scenarios were designed to be realistic for a student population. Participants were asked to read each of the hypothetical scenarios and were instructed to think about how the actor in the scenario was likely to feel. All participants read each of the eight vignettes in a randomized order.

\section{Materials.}

\section{Vignettes.}

1. Stable + controllable + intrapersonal

Sam has never put much effort into his appearance (i.e., does not care about what he wears). Sam has been applying for summer jobs with the government and has had a few interviews. Due to Sam's poor choice of clothing, he does not look professional at his interviews. As a result, he does not get hired for any summer job and struggles to pay his bills.

2. Stable + controllable + interpersonal

Harper takes out student loans each year in order to pay for her tuition and school related expenses. Harper has always had a very impulsive personality. Every time she receives a student loan payment, she parties like there is no tomorrow, even though she knows that she needs the money. As a result of spending her student loan money on partying with her friends, Harper is unable to make her portion of rent payments and all of her roommates get evicted from their shared apartment.

3. Stable + uncontrollable + interpersonal 
Keegan and his friends signed up for a volleyball tournament in the summer. The whole team committed to training for the tournament because there is a large cash prize for the top three teams. Keegan realizes what a big deal the tournament is so he goes to the gym and often practices his volleyball skills. However, Keegan is shorter than his friends and does not have much natural athletic talent. Despite his best effort, Keegan's poor volleyball skills cost his team the cash prize.

4. Stable + uncontrollable + intrapersonal

Blake has never had much natural talent (i.e., been smart) in English. Blake recently had an important English exam and she studied hard for it but it still seemed very difficult for her. Even though Blake had done everything she could to prepare, she just found out she did badly on the exam, much worse than others in the class.

5. Unstable + controllable + interpersonal

Rory has a group project in his Biology class. Although Rory knows that the project is a big part of his final grade and that his team members are counting on him, the night before it is due Rory chooses to go to a party. He ends up getting drunk and is unable to finish his part of the assignment. Since Rory's part of the assignment was incomplete, the team received a poor grade.

6. Unstable + controllable + intrapersonal

Jordan recently started watching a new show on Netflix that she really enjoyed. She has an important test coming up but she chooses to finish the Netflix series instead of study. On the day of the test she realized that she was not prepared. Jordan was so nervous that she would fail the test that she decided to cheat by looking at her notes. Jordan got caught for cheating and received a failing grade in the class as a result.

7. Unstable + uncontrollable + interpersonal 
Ryan's best friend, Casey, was turning 20 and was coming from out of town to celebrate his birthday with Ryan. They had planned to go for dinner at Casey's favourite restaurant and then to a hockey game to watch his favourite team. On the morning that Casey arrived, Ryan slipped on ice and broke his arm. He needed to go to the hospital to get surgery and was no longer able to celebrate Casey's birthday with him.

\section{Unstable + uncontrollable + intrapersonal}

Sawyer had been feeling quite sick for a few days and needed to go to the doctor to get medication. She decided to drive to the doctor's office to get the medication. On her drive to the doctor's office, Sawyer suddenly felt very dizzy and crashed her car into a street lamp on the side of the road and damaged her car.

Primary emotions. Participants in the continuous version of the study were asked "following this experience, to what extent is 'the actor' feeling each of the following emotions: shame, guilt, sadness, and anxiety?" on a scale ranging from 1 (not at all) to 5 (very much so) and participants in the multiple choice version of the study were asked "following this experience, what is the primary emotion 'the actor' is likely feeling?".

Forgiveness seeking. For the interpersonal scenarios, participants were asked "to what extent will 'the actor' desire forgiveness from the other person(s) in the scenario?'. In both the interpersonal and intrapersonal scenarios, participants were asked "to what extent will 'the actor' desire forgiveness from the self? Participants responded on a scale ranging from 1 (not at all) to 5 (very much so). 1

1. Self-fogiveness seeking was measured in study 1 . However, after realizing that there were conceptual problems with the wording of this item, I decided to exclude this variable from analyses. Self-forgiveness granting will be further discussed in study 3 . 
Demographics. Age, sex, and one's level of empathy 2 (using the perspective taking subscale of the Interpersonal Reactivity Index; IRI, Davis, 1980) were included as potential moderators.

\section{Results}

The first purpose of study 1 was to determine whether to assess emotions in a continuous or multiple-choice response style by testing whether participants were differentially distinguishing between emotions in the two versions of the study. First, frequencies were run for the multiple-choice version of the study. For the first four scenarios of interest, it appeared as though participants were dinstinguishing between emotions in the expected direction in some but not all scenarios. Specifically, participants perceived shame more often than guilt in both stableuncontrollable scenarios but this distinction was greater in the intrapersonal scenario. In the unstable-controllable scenarios, participants perceived more guilt than shame in the interpersonal scenario, but more shame than guilt in the intrapersonal scenario. Participants were choosing alternative emotions at a surprisingly high frequency (Table 1).

2 Empathy was measured in order to explore whether one's level of empathy would moderate one's ability to distinguish between shame and guilt. Since empathy was not found to be a moderator, empathy will not be discussed further and will not be included in future studies. 


\section{Table 1}

Assessments of primary emotions in scenarios

\begin{tabular}{|c|c|c|c|}
\hline & Shame (\%) & Guilt (\%) & $\begin{array}{l}\text { Other - Anxiety or } \\
\text { Sadness (\%) }\end{array}$ \\
\hline $\begin{array}{l}\text { Stable + uncontrollable } \\
+ \text { interpersonal (S) }\end{array}$ & 42.9 & 38.1 & 19.0 \\
\hline $\begin{array}{l}\text { Stable + uncontrollable } \\
+ \text { intrapersonal (S) }\end{array}$ & 35.7 & 2.4 & 61.9 \\
\hline $\begin{array}{l}\text { Unstable }+ \text { controllable } \\
+ \text { interpersonal }(G)\end{array}$ & 28.6 & 64.3 & 7.1 \\
\hline $\begin{array}{l}\text { Unstable }+ \text { controllable } \\
+ \text { intrapersonal }(G)\end{array}$ & 50.0 & 35.7 & 14.3 \\
\hline $\begin{array}{l}\text { Unstable }+ \\
\text { uncontrollable }+ \\
\text { intrapersonal }\end{array}$ & 7.1 & 9.5 & 83.3 \\
\hline $\begin{array}{l}\text { Unstable }+ \\
\text { uncontrollable }+ \\
\text { interpersonal }\end{array}$ & 2.4 & 21.4 & 76.2 \\
\hline $\begin{array}{l}\text { Stable }+ \text { controllable }+ \\
\text { intrapersonal }\end{array}$ & 23.8 & 2.4 & 73.8 \\
\hline $\begin{array}{l}\text { Stable }+ \text { controllable }+ \\
\text { interpersonal }\end{array}$ & 42.9 & 42.9 & 14.3 \\
\hline
\end{tabular}

Note. $N=42$. (S) represents the scenarios in which a greater level of shame, compared to guilt, was expected. (G) represents the scenarios in which a greater level of guilt, compared to shame, was expected.

For the continuous version of the study, correlations were run for each scenario to determine whether participants were distinguishing between the four emotions. Each of these correlation coefficients was transformed using Fisher's ' $r$ to $z$ ' transformation and then averaged across the eight scenarios. The average transformed correlation was then converted back to $r$ (Table 2). Correlations between shame, anxiety and sadness and between guilt, anxiety and 
sadness ranged from .383 to .527 , suggesting that participants were distinguishing between these emotions. It also appeared as though participants were distinguishing between shame and guilt $(r$ $=.629$ ). These correlation coefficients suggest a degree of discriminant validity between the four emotions.

\section{Table 2}

Bivariate correlations between emotions (shame, guilt, sadness, anxiety), averaged across vignettes

\begin{tabular}{lllll}
\hline & Shame & Guilt & Anxiety & Sadness \\
\hline Shame & 1 & $.629^{* *}$ & $.434^{*}$ & $.527^{* *}$ \\
Guilt & 1 & $.407^{*}$ & $.496^{* *}$ \\
Anxiety & & 1 & $.383^{*}$ \\
Sadness & & & 1 \\
\hline
\end{tabular}

Note. ${ }^{*} \mathrm{p}<.05,{ }^{* *} \mathrm{p}<.01$ (two-tailed), $N=37$.

The second purpose of study 1 was to assess the causal antecedents of shame and guilt. Using the continuous version of the study, a series of 2 (guilt/shame) $\times 2$ (interpersonal/intrapersonal) repeated measures ANOVAs was conducted to determine whether stable-uncontrollable scenarios elicited more guilt than shame, whether unstable-controllable scenarios elicited more shame than guilt, and whether there was an interaction between perceieved emotions and whether the transgression was interpersonal or intrapersonal (type of transgression).

In the unstable-controllable scenarios, there was no statistically significant difference between participants' perceived levels of guilt $(M=4.54, S E=.13)$ and shame $(M=4.49, S E=$ $.13), F(1,36)=0.39, p=.534, \eta_{\mathrm{p} 2}=.011$. There was a slight trend suggesting that participants perceived a greater level of shame and guilt in the intrapersonal scenarios $(M=4.54, S E=.13)$ 
compared to the interpersonal scenarios $(M=4.38, S E=.17), F(1,36)=2.25, p=.143, \eta_{\mathrm{p} 2}=$ .059 . The two way interaction between emotion and type of transgression was not statistically significant, $F(1,36)=1.24, p=.273, \eta_{\mathrm{p} 2}=.033$. In the interpersonal scenarios there was a comparable level of perceived guilt $(M=4.46, S E=.17)$ and shame $(M=4.30, S E=.19)$.

Likewise, there was a comparable level of perceived guilt $(M=4.62, S E=.15)$ and shame $(M=$ $4.68, S E=.14)$ in the intrapersonal scenarios (Figure 1).

\section{Figure 1}

Interaction between emotion and type of transgression in unstable-controllable scenarios (Study 1)

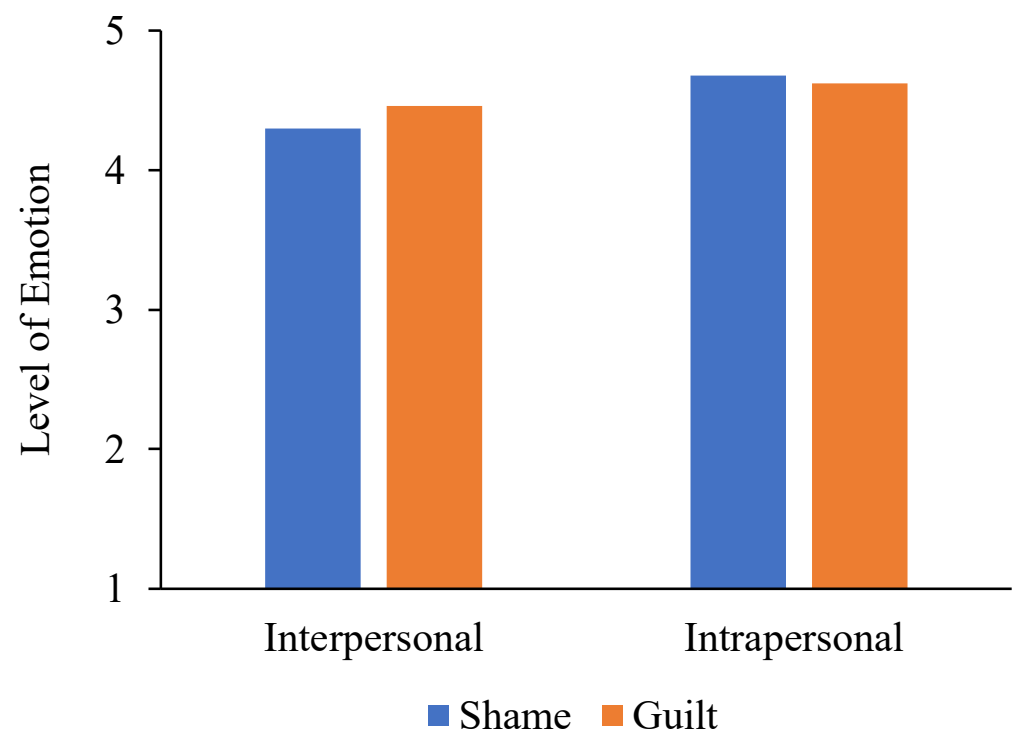

Note. $N=37$.

For the stable-uncontrollable scenarios, there was a significant main effect of emotion, $F(1,36)=25.48, p<.001, \eta_{\mathrm{p} 2}=.414$. As hypothesized, participants perceived a greater level of shame $(M=3.78, S E=.18)$ compared to guilt $(M=3.16, S E=.17)$. There was also a main effect of whether the transgression was interpersonal or intrapersonal, $F(1,36)=8.11, p=.007, \eta_{\mathrm{p} 2}=$ .184. Participants perceived a greater level of shame and guilt when scenarios were interpersonal $(M=3.70, S E=.17)$ compared to when scenarios were intrapersonal $(M=3.24, S E=.19)$. These 
main effects were qualified by a two-way interaction between emotion and type of transgression, $F(1,36)=18.20, p<.001, \eta_{\mathrm{p} 2}=.336$. As expected, participants perceived a greater level of shame $(M=3.84, S E=.22)$ compared to guilt $(M=2.65, S E=.22)$ when the scenario was intrapersonal but only a slightly greater level of shame $(M=3.73, S E=.18)$ compared to guilt $(M=3.68, S E=.19)$ when the scenario was interpersonal. Although there were similar levels of shame in both scenarios, levels of perceived guilt were lower in the intrapersonal scenario; there was a smaller discrepancy between perceived shame and guilt. The emotion by type of transgression interaction was analyzed using simple main effects analysis. Levels of perceived shame and guilt differed in the intrapersonal scenario, $F(1,36)=32.66, p<.001, \eta_{\mathrm{p} 2}=.476$, but levels of perceived shame and guilt did not differ in the interpersonal scenario, $F(1,36)=.13, p=$ $.720, \eta_{\mathrm{p} 2}=.004$ (Figure 2).

\section{Figure 2}

Interaction between emotion and type of transgression in stable-uncontrollable scenarios (Study 1)

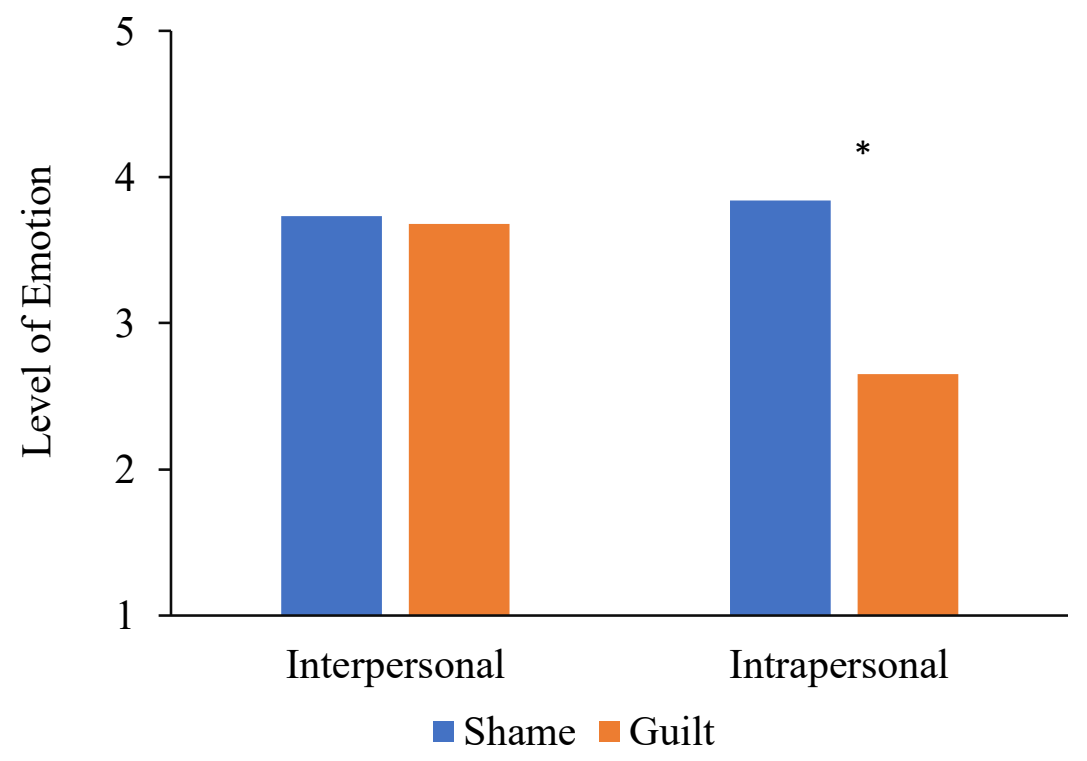

Note. $N=37, * p<.001$. 
To explore whether participants perceived that individuals would be more motivated to seek forgiveness from others when interpersonal scenarios involved unstable-controllable causal attributions compared to stable-uncontrollable causal attributions, a paired-samples t-test was conducted. There was no statistically significant difference between seeking forgiveness from others in unstable-controllable scenarios $(M=4.14, S D=1.18)$ and stable-uncontrollable scenarios $(M=3.86, S D=0.98), t(36)=-0.96, p=.343$. Bivariate correlations were conducted to explore whether guilt and shame were associated with perceived likelihood of seeking forgiveness from others. Guilt was associated with perceived forgiveness seeking in the stableuncontrollable scenarios $(r=.564, \mathrm{p}<.001)$ and unstable-controllable scenarios $(r=.502, p=$ .002). Shame was also associated with perceived forgiveness seeking in the stable-uncontrollable scenarios $(r=.524, p=.001)$ and the unstable-controllable scenarios $(r=.623, p<.001)$. In order to assess whether levels of perceived guilt predicted perceived likelihood of forgiveness seeking from others over and above perceived shame a series of regressions was conducted. In the stable-uncontrollable scenario, guilt $(\beta=.39, p=.05)$ but not shame $(\beta=.26, p=.18)$ significantly predicted seeking forgiveness from others, $\left.R_{2}=.35, F(2,34)=9.27, p=.001\right)$. However, in the unstable-controllable scenario, shame $(\beta=.54, p=.008)$ but not guilt $(\beta=.12, p$ $=.53)$ significantly predicted seeking forgiveness from others, $R_{2}=.40, F(2,34)=11.09, p<$ $.001)$.

\section{Discussion}

The purposes of study 1 were to assess whether unique combinations of causal attributions are differentially associated with shame and guilt, and to assess whether attributions and emotions are differentially associated with perceived likelihood of forgiveness seeking. The results from study 1 suggest that although participants are choosing alternative emotions (sadness 
and anxiety) at a fairly high frequency in the multiple choice version of the study, both versions display some evidence of discriminant validity. It is possible that when forced to choose one emotion, in the multiple-choice response method, participants are choosing sadness because Weiner (1985) suggests that sadness is an initial outcome-related emotion to negative outcomes. Therefore, if participants are not thinking about the causes of the negative outcomes, sadness might be the initial reaction.

Using only the data obtained from the continuous response version of the study, as hypothesized, when an actor's behaviour was described as stable and uncontrollable, participants perceived that the actor would feel more shame than guilt. There was a greater distinction between shame and guilt in the intrapersonal scenario - guilt was much lower than shamewhereas levels of shame and guilt were comparable in the interpersonal scenario. Contrary to my hypothesis and Weiner's (1985) model, when an actor's behaviour was unstable and controllable, participants did not seem to differentiate between levels of shame and guilt; the mean for shame and guilt were similar. Due to the small effect size, it is unlikely that the null effect for the unstable-controllable scenarios was attributable to a small sample size. It is possible that participants were not differentiating between shame and guilt in this condition due to an ineffective manipulation of the stability and controllability dimensions. Participants may not have interpreted these transgressions as attributable to unstable and controllable causes. It is also possible that the shame-guilt distinction does not exist in the way that theory suggests. People might believe that it is possible to feel more shame than guilt, but not possible to feel more guilt than shame (if one feels guilt they simultaneously or subsequently feel similar levels of shame).

Although levels of perceived likelihood of forgiveness seeking were slightly higher in unstable-controllable scenarios compared to stable-uncontrollable scenarios, this difference was 
not statistically significant. Findings suggest that whether the attribution was stableuncontrollable or unstable-controllable did not influence participants' perceived likelihood of seeking forgiveness from the victim. Furthermore, guilt and shame were both positively associated with perceived likelihood of seeking forgiveness from victims. However, guilt only predicted likelihood of forgiveness seeking over and above shame in the stable-uncontrollable scenario. Contrarily, shame predicted seeking forgiveness over and above shame in the unstablecontrollable scenario. It is possible that these null and opposite findings are partly because the causal attributions did not distinguish shame and guilt as expected.

Upon reflection it became apparent that there may have been some ambiguity with the scenarios. For instance, whereas some scenarios had implications for academic success, others had greater implications for friendships and sports. Some scenarios may have been interpreted as more morally wrong (i.e., getting drunk instead of finishing an assignment) than others (e.g., doing badly at sports because of natural lack of ability). Acknowledging these weaknesses, a second study was conducted.

\section{Study 2}

There were a few concerns with study 1. First, with one exception, it did not seem as though participants were distinguishing between shame and guilt as hypothesized. Second, with one exception, my hypotheses on forgiveness seeking were not supported. One explanation for this is the potential ambiguity of the scenarios provided to participants. A second study was conducted in attempts to address this possibility.

Following the first study, I recognized that I was less concerned about main effects of controllability and stability, and more interested in how the combination of these two attributions distinguish shame and guilt. Thus, in an effort to reduce the number of scenarios and with the 
hopes that less reading would encourage participants to carefully think about each of the provided scenarios, the eight scenarios were reduced to four (interpersonal and intrapersonal guilt and shame eliciting scenarios). Furthermore, because it was unclear whether we were manipulating the attributions in such a way that would replicate Weiner's distinction, adjustements were made to the remaining four scenarios in attempts to make the stability and controllability dimensions more clear. All scenarios were changed to involve academic issues so that outcomes were similar across scenarios. Lastly, because Weiner (1985) suggests that sadness is an initial outcome-related emotion to negative outcomes, I changed the emotion response option of sadness to anger, which is an emotion that also follows unique causal attributions.

The purpose of study 2 was to determine whether the scenarios were manipulating dimensions in a way that is consistent with Weiner's shame-guilt distinction. Participants were only presented with four vignettes, each followed by a measure assessing the extent to which they believed the actor was feeling shame, guilt, anger, and anxiety through the use of a Likert scale. I chose to use a Likert scale to test emotion because this accounts for the fact that some scenarios likely elicit some degree of both shame and guilt. In the second study, I did not measure forgiveness seeking. The purpose of study 2 was to assess whether adjusting the manipulations of stability and controllability would help to differentiate shame and guilt. This was a precursor to assessing my research question - whether shame/guilt inducing attributions predict forgiveness seeking behaviours. Thus, before reintroducing forgiveness seeking measures, I focused on implementing a more powerful manipulation of attributions.

I again hypothesized that participants would perceive that the perpetrator would feel more guilt than shame in unstable-controllable scenarios and more shame than guilt in stableuncontrollable scenarios. 


\section{Method}

\section{Participants and procedure.}

Participants included a new sample of undergraduate students from Carleton University $\left(N=67, M_{\text {age }}=20.07, S D_{\text {age }}=6.27, \%\right.$ female $\left.=82.1\right)$. Participants read a series of hypothetical scenarios describing situations in which a transgression has occurred. The scenarios varied the extent to which the cause of the transgression appeared to be stable or unstable, controllable or uncontrollable, and whether the primary victim was the transgressor (intrapersonal) or another person(s) (interpersonal). Scenarios were designed to be realistic for a student population. Participants were asked to read each of the hypothetical scenarios and were instructed to think about how the actor in the scenario was likely to feel. All participants read each of the four vignettes in a randomized order.

\section{Materials.}

\section{Vignettes.}

1. Stable + uncontrollable + interpersonal Keegan registered for an English course. The final assignment for the course was a group presentation in front of the class. Keegan has always been terrified of public speaking and has never felt comfortable talking to strangers. However, Keegan does not want to let his group down. He spends as much time as possible practicing his part of the presentation so that he is ready for presentation day. Even though Keegan tried his best, on presentation day he was so nervous that he was unable to present his part of the project. As a result, his team looked unprepared and he just found out his whole team received a very poor grade.

2. Stable + uncontrollable + intrapersonal 
Blake has never had much natural talent (i.e., been smart) in math. Even though she has always tried to improve, math has always been her worst subject. Blake has an important math exam coming up and she knows how important this grade will be for her GPA. Blake studies every day for it and also registers for tutoring but it still seems very difficult for her. Even though Blake did everything she could to prepare, she just found out she did very badly on the exam, much worse than others in the class.

3. Unstable + controllable + interpersonal

Rory has a group lab report due in his Biology class. Although Rory knows that this lab report is a big part of the final grade in the course and that her team members are counting on her, the night before it is due Rory chooses to go to a party. She chooses to stay out late and get drunk with her friends. As a result, she does not finish her part of the assignment. Rory just found out that because her part of the assignment was incomplete, the whole team received a very poor grade on the group assignment.

4. Unstable + controllable + intrapersonal

Jordan recently started watching a new show on Netflix that he really enjoys. He knows he has a psychology test coming up but she chooses to finish the Netflix series instead of study. On the day of the test he realized that he had not studied at all and was not prepared. Because he chose not to study, Jordan was worried that he would fail the test. He decided to cheat during the test by looking at his notes. Jordan got caught for cheating and just found out that he received a failing grade in the course as a result.

Primary emotions. Participants were asked "following this experience, to what extent is "the actor' feeling each of the following emotions: shame, guilt, anger, and anxiety?" on a scale ranging from 1 (not at all) to 5 (very much so). 


\section{Results}

A first $2 \times 2$ repeated measures ANOVA was conducted to determine whether unstablecontrollable attributions elicit greater levels of perceived guilt compared to shame. In these scenarios, there was no statistically significant difference between participants' perceived levels of guilt $(M=4.41, S E=.13)$ and shame $(M=4.37, S E=.12), F(1,66)=0.24, p=.626, \eta_{\mathrm{p} 2}=$ .004. There was also no statistically significant difference in whether participants perceived greater levels of shame and guilt in intrapersonal scenarios $(M=4.43, S E=.12)$ compared to the interpersonal scenarios $(M=4.36, S E=.13), F(1,66)=0.60, p=.443, \eta_{\mathrm{p} 2}=.009$. However, there was a statistically significant two-way interaction between emotion and type of transgression, $F(1,66)=9.43, p=.003, \eta_{\mathrm{p} 2}=.125$. As expected, participants perceived a greater level of guilt $(M=4.48, S E=.14)$ compared to shame $(M=4.24, S E=.14)$ when the unstable-controllable scenario was interpersonal. However, in the intrapersonal scenario, this did not hold true. Rather, participants perceived a slightly greater level of shame $(M=4.51, S E=.12)$ compared to guilt $(M=4.34, S E=.14)$. The emotion by type of transgression interaction was analyzed using simple main effects analysis. Levels of perceived shame and guilt differed in the interpersonal scenario, $F(1,66)=8.36, p=.005, \eta_{\mathrm{p} 2}=.112$, but levels of perceived shame and guilt did not significantly differ in the intrapersonal scenario, $F(1,66)=2.01, p=.161, \eta_{\mathrm{p} 2}=.030$ (Figure 3 ). 


\section{Figure 3}

Interaction between emotion and type of transgression in unstable-controllable scenarios (Study 2)

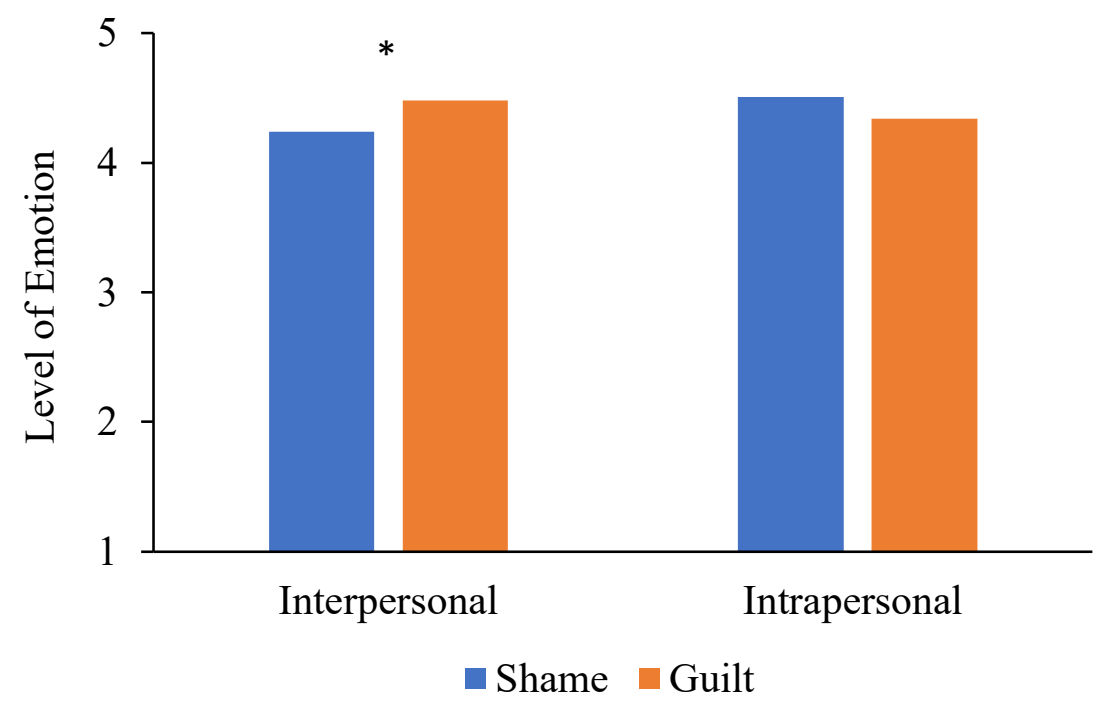

Note. $N=67, p<.01$.

A second 2x2 repeated measures ANOVA was conducted to determine whether stableuncontrollable attributions elicit greater perceived levels of shame compared to guilt. In these scenarios, there was a significant main effect of emotion, $F(1,64)=57.26, p<.001, \eta_{\mathrm{p} 2}=.472$. As hypothesized, participants perceived a greater level of shame $(M=4.03, S E=.11)$ compared to guilt $(M=3.20, S E=.10)$. There was also a main effect of whether the transgression was interpersonal or intrapersonal, $F(1,64)=201.25, p<.001, \eta_{\mathrm{p} 2}=.759$. Participants perceived a greater level of shame or guilt when scenarios included interpersonal consequences $(M=4.35$, $S E=.09)$ compared to when scenarios were intrapersonal $(M=2.89, S E=.12)$. These main effects were qualified by a two-way interaction between emotion and type of transgression, $F(1,64)=52.28, p<.001, \eta_{\mathrm{p} 2}=.450$. As expected, participants perceived a greater level of shame $(M=3.69, S E=.16)$ compared to guilt $(M=2.08, S E=.14)$ when the scenario was intrapersonal. Although participants also perceived a greater level of shame $(M=4.37, S E=.11)$ 
compared to guilt $(M=4.32, S E=.12)$ when the scenario was interpersonal, there was a much smaller discrepancy between perceived shame and guilt in the interpersonal scenario compared to the intrapersonal scenario. The emotion by type of transgression interaction was analyzed using simple main effects analysis. Levels of perceived shame and guilt differed in the intrapersonal scenario, $F(1,64)=89.43, p<.001, \eta_{\mathrm{p} 2}=.583$, but levels of perceived shame and guilt did not differ in the interpersonal scenario, $F(1,64)=.115, p=.735, \eta_{\mathrm{p} 2}=.002$ (Figure 4).

\section{Figure 4}

Interaction between emotion and type of transgression in stable-uncontrollable scenarios (Study 2)

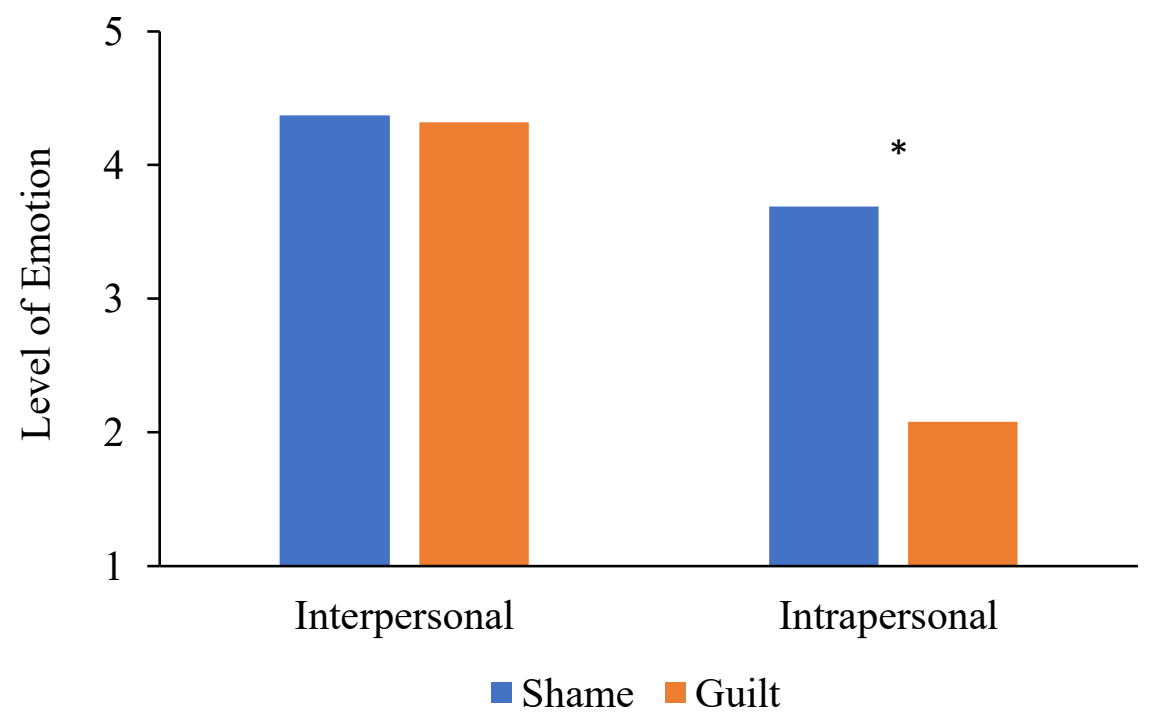

Note. $N=65, * p<.001$.

\section{Discussion}

The purpose of the second study was to assess whether making the dimensions of controllability and stability clearer in the scenarios would strengthen the manipulations and help to distinguish between shame and guilt as expected, based on Weiner's theory. Contrary to my hypothesis and consistent with the first study, when an actor's behaviour was unstable and 
controllable, there was still no significant main effect of emotion - there were comparable levels of perceived shame and guilt. Perceived levels of guilt were greater than shame only in the interpersonal scenario. In the intrapersonal scenario, shame and guilt did not significantly differ. This is inconsistent with prior research which has found that guilt tends to be greater than shame in unstable, controllable, and intrapersonal scenarios (Tracy \& Robins, 2006). This discrepancy with prior research could be due to the scenario used in this study. This scenario involved a student who cheated on a test because the student chose to procrastinate and was completely unprepared. It is possible that some participants may have interpreted that, although the choice to procrastinate was controllable, the choice to cheat was uncontrollable because the student would have otherwise failed. An uncontrollable attribution would increase levels of shame according to Weiner. However, it remains possible that participants simply are not distinguishing between shame and guilt in this condition, which would suggest that unstable and controllable attributions elicit greater guilt than shame only in interpersonal scenarios.

The results for the stable-uncontrollable transgressions were also consistent with study 1 and were consistent with my hypotheses. When an actor's behaviour was stable and uncontrollable, there was a greater level of perceived shame compared to guilt. However, this distinction was only evident in the intrapersonal scenario; in the interpersonal scenario, perceived levels of shame and guilt did not significantly differ. According to my knowledge, this is the first study to use interpersonal vignettes to test whether unique attributions distinguish between shame and guilt. Therefore, it is possible that people do not believe that shame and guilt differ when a stable-uncontrollable attribution also involves interpersonal consequences. Perhaps when hurting others, regardless of the attribution, levels of guilt will be high as a means to motivate relationship repair. 
In conclusion, results from both versions of study 1 (multiple choice and continuous response options) and study 2 (which replaced sadness with anger as an emotion option and adjusted scenarios) seem to suggest that Weiner's (1985) distinction between shame and guilt are only applicable for interpersonal events when attributions are unstable-controllable and only for intrapersonal events when attributions are stable-uncontrollable.

\section{Study 3}

In both studies 1 and 2, the small observed effect sizes associated with the non-significant effects of emotion suggest that the null findings are not a simple matter of sample size. Based on these effect sizes a very large sample size (in the thousands) would be necessary to produce significant main effects as expected. Therefore, either these findings suggest that there is no consistent difference between shame and guilt in unstable-controllable-intrapersonal or stableuncontrollable-interpersonal situations or that the manipulations are not powerful enough to produce adequate effect sizes. In study 3 scenarios were revised in an attempt to again make the attribution manipulation as clear as possible for participants while keeping all aspects of the scenario constant except the cause of the negative outcome. Furthermore, the new scenarios described outcomes that reflect moral transgressions to a greater extent than the previous scenarios. Instead of using academic failure, which some students might value more than others, a car crash was used as the outcome of the scenarios. Lastly, although I intentionally varied the gender of the actors in the scenarios in studies 1 and 2 , such that there was equal representation of females and males, gender of the actors in the scenarios was not randomized. Recognizing that the gender of the actors in the scenarios may have influenced participant's perceptions, all pronouns were removed from the scenarios in study 3. Using the new vignettes (described below), I again hypothesized that unstable-controllable attributions would elicit greater perceived 
guilt than shame and that stable-uncontrollable attributions would elicit greater perceived shame than guilt.

Furthermore, I reintroduced measures of forgiveness seeking. I again hypothesized that, within interpersonal transgressions, people would perceive a greater likelihood of forgiveness seeking following presumed guilt inducing attributions (unstable-controllable) compared to presumed shame inducing attributions (stable-uncontrollable). I also predicted that people would perceive a greater likelihood of forgiveness seeking when they also perceived a greater level of guilt compared to shame from the perpetrator; guilt would predict forgiveness seeking over and above shame but shame should not predict forgiveness seeking over and above guilt.

In addition to forgiveness seeking, I also assessed whether attributions and emotions predicted likelihood of self-forgiveness. Self-forgiveness is defined as a "willingness to abandon self-resentment in the face of one's own acknowledged objective wrong, while fostering compassion, generosity, and love toward oneself" (Enright, 1996, p. 115). An ability to forgive oneself has been negatively associated with anxiety, depression, and hostility, and positively associated with self-esteem and life satisfaction (Coates, 1997; Leach \& Lark, 2004; Maltby, Macaskill, \& Day, 2001; Mauger et al., 1992). Hall and Fincham (2008) found that guilt was both inversely associated with self-forgiveness at time one and increases in guilt were associated with less self-forgiveness, beyond the change accounted for by the self-forgiveness trajectory. However, shame at time one and changes in shame were unrelated to self-forgiveness (Hall \& Fincham, 2008). Hall and Fincham also examined 'forgiveness-inhibiting attributions' (internal, stable, and global) and 'forgiveness-promoting attributions' (external, unstable, and specific). They found that the forgiveness-inhibiting attributions were inversely associated with selfforgiveness at time one, but changes in attributions were not related to self-forgiveness. 
Based on the research by Hall and Fincham (2008) and the research suggesting that shame and guilt are both distressing and depressing emotions (Wicker, Payne, \& Morgan, 1983), I hypothesized that perceptions of both shame and guilt would be inversely correlated with perceived likelihood of self-forgiveness; greater shame and greater guilt would predict less selfforgiveness. I further explored whether following an imagined scenario. Based on Lewis' (1971) theory, I expected that individuals would be less likely to forgive themselves when they perceived higher levels of shame, compared to guilt, as it might be harder to forgive the self when the self (shame), rather than the behaviour (guilt), is viewed as the focal cause. However, Hall and Fincham's (2008) findings suggest that individuals should be less likely to forgive themselves when they also perceive a higher level of guilt relative to shame. This study assessed the extent to which perceptions of shame and guilt predicted perceived likelihood of selfforgiveness, and to the extent that they did, which aforementioned perspective was supported. If Lewis (1971) is correct, I expected that perceived shame (but not guilt) would predict low levels of self-forgiveness. If Hall and Fincham (2008) are correct, I expected that perceived guilt (but not shame) would predict low levels of self-forgiveness.

I also explored whether presumed shame inducing attributions (stable-uncontrollable) and presumed guilt inducing attributions (unstable-controllable) influenced one's perceived ability to forgive onself. Lastly, I hypothesized that participants would report a greater likelihood of selfforgiveness in intrapersonal scenarios compared to interpersonal scenarios. I predicted this because transgressions may carry a larger burden and self-forgiveness might be more difficult when transgressions involve hurting other victims in addition to the self.

\section{Method}

\section{Participants and procedure.}


In Study 3, a new sample of 179 undergraduate students from Carleton University was recruited. All participants were compensated with .25\% course credit. Thirty-three participants were excluded for completing the questionnaire in less than three minutes on the assumption that such respondents were not able to read and think about the scenarios in less than three minutes. Another four participants were excluded for having reported being under the English fluency criteria for the current study or for failing to respond to this item. This left a final sample of 142 $\left(M_{\text {age }}=20.55, S D_{\text {age }}=4.70, \%\right.$ female $\left.=71.1\right)$. The sample size was determined based on a power analysis that indicated that a sample of $\mathrm{N}=140$ would be sufficient to detect an effect size of .1 with power of .80. I sampled beyond this number based on the assumption that some of the participants would be excluded from the current study.

After reading the informed consent form and agreeing to participate, participants read a series of hypothetical scenarios describing situations in which a transgression had occurred. The scenarios varied the extent to which the cause of the transgression appeared to be stable or unstable, controllable or uncontrollable, and whether the primary victim is the transgressor (intrapersonal) or another person(s) (interpersonal). Participants were asked to read each of the hypothetical scenarios and were instructed to think about how the actor in the scenario was likely to feel and act. All participants read each of the four vignettes in a randomized order.

\section{Materials.}

\section{Vignettes.}

1. Stable-uncontrollable-interpersonal vignette:

Keegan owns a car. Keegan was driving with three friends in the passenger seats. Keegan knows it is important to stay focused on the road and tries hard to do so. However, Keegan has always had a hard time paying attention while driving and has had many minor car accidents as a result. 
Recently, Keegan was distracted and lost control of the car. The car smashed into a lamp post on the side of the road. Keegan's car was damaged and Keegan and the three friends in the car suffered injuries. No other cars were involved in the accident.

2. Stable-uncontrollable-intrapersonal vignette:

Blake owns a car. Blake was driving alone. Blake knows it is important to stay focused on the road and tries hard to do so. However, Blake has always had a hard time paying attention while driving and has had many minor car accidents as a result. Recently, Blake was distracted and lost control of the car. The car smashed into a lamp post on the side of the road. Blake's car was damaged and Blake suffered injuries. No other cars were involved in the accident.

3. Unstable-controllable-interpersonal vignette:

Rory owns a car. Rory was driving with three friends in the passenger seats. Rory knows that texting and driving is illegal and usually tries not to look at text messages while driving. However, while driving, Rory received a text message and Rory decided to answer this text while still driving. Texting and driving caused Rory to lose control of the car and the car smashed into a lamp post on the side of the road. Rory's car was damaged and everyone in the car suffered injuries. No other cars were involved in the accident.

4. Unstable-controllable-intrapersonal vignette:

Jordan owns a car. Jordan was driving alone. Jordan knows that texting and driving is illegal and usually tries not to look at text messages while driving. However, while driving, Jordan received a text message and Jordan decided to answer this text while still driving. Texting and driving caused Jordan to lose control of the car and the car smashed into a lamp post on the side of the road. Jordan's car was damaged and Jordan suffered injuries. No other cars were involved in the accident. 
Shame and Guilt. Perceived levels of shame and guilt were measured using a few items from the State Shame and Guilt Scale (SSGS; Marschall, Saftner, \& Tangney, 1994) and through items directly asking about perceived levels of shame and guilt. Specifically, to assess levels of perceived guilt, participants were asked about how likely the actor is to feel remorse and regret, to feel bad about something he or she did, and to feel guilt. To assess levels of perceived shame, participants were asked about how likely the actor is to feel humiliated and disgraced, to feel like a bad person, and to feel shame. All items were measured using a Likert scale ranging from 1 (not at all) to 5 (very much so). Cronbach's alpha was measured for shame and guilt measures in all four vignettes and the average of these Cronbach's alphas were calculated. The current study found an average Cronbach's alpha of $\alpha=.81$ for the shame measure and an average Cronbach's alpha of $\alpha=.82$ for the guilt measure.

The decision to include items from the SSGS in the measures of shame and guilt was to strengthen the assessment of these emotions. The use of single item measures of shame and guilt in studies one and two may have presented a lack of fidelity. Thus, including additional items to measure shame and guilt attempted to address this issue.

Forgiveness seeking. In the interpersonal scenarios, participants were asked "following this experience, to what extent will 'the actor' desire forgiveness from the friends that were in the car?". This item was measured using a Likert scale ranging from 1 (not at all) to 5 (very much SO).

Self-forgiveness. In all scenarios, participants were asked "following this experience, to what extent will 'the actor' desire forgiveness from himself/herself?". Those participants who indicated that the actor would desire at least some degree of self-forgiveness were then asked 
“to what extent will 'the actor' forgive himself/herself?". Both items were measured using a Likert scale ranging from 1 (not at all) to 5 (very much so).

Demographics. Age, sex, and one's level of English comprehension were measured. English comprehension was measured through asking participants "to what extent do you understand and read the English language?". Participants responded using a Likert scale ranging from 1 (not very well) to 4 (very well). Those who scored less than 3 (quite well) were excluded from the analysis.

\section{Results}

Correlations between the three guilt items and three shame items were run for each scenario to determine whether participants were distinguishing between shame and guilt and to determine the association between the items assessing shame and guilt. Each of these correlation coefficients was transformed using Fisher's ' $r$ to $z$ ' transformation and then averaged across the four scenarios. The average transformed correlations were then converted back to $r$ (Table 3). Correlations between all items ranged from .468 to .707 . The single-item measures of shame and guilt were significantly and positively correlated, $r=.638, p<.001$. The single-item measure of guilt was slightly (but not significantly) more highly correlated with the two guilt items from the SSGS $(r=.606, r=.611)$ compared to the two SSGS shame items $(r=.563, r=.595)$. The single-item shame measure was more strongly correlated with one of the SGSS shame items (humiliated/disgraced) than was the single-item guilt measure $(r=.707 v s r=.563 ; t(139)=$ $2.83, p<.01)$, but this was not the case with the second SSGS shame item $(r=.599$ vs. $r=.595)$. 


\section{Table 3}

Bivariate correlations between items assessing shame and guilt averaged across vignettes

\begin{tabular}{|c|c|c|c|c|c|c|}
\hline & 1 & 2 & 3 & 4 & 5 & 6 \\
\hline 1.Feel shame & 1 & .638 & .560 & .556 & .707 & .599 \\
\hline 2.Feel guilt & & 1 & .606 & .611 & .563 & .595 \\
\hline $\begin{array}{l}\text { 3.Feel } \\
\text { remorse and } \\
\text { regret }(G)\end{array}$ & & & 1 & .640 & .470 & .513 \\
\hline $\begin{array}{l}\text { 4.Feel bad } \\
\text { about } \\
\text { something }(G)\end{array}$ & & & & 1 & .468 & .568 \\
\hline $\begin{array}{l}\text { 5.Feel } \\
\text { humiliated } \\
\text { and disgraced } \\
\text { (S) }\end{array}$ & & & & & 1 & .550 \\
\hline $\begin{array}{l}\text { 6.Feel like a } \\
\text { bad person (S) }\end{array}$ & & & & & & 1 \\
\hline
\end{tabular}

Note. All correlations are $\mathrm{p}<.001$ (two-tailed), $N=141$ (averaged across all correlations).

Ratings of perceived shame and guilt were highly negatively skewed. Skewness for shame ranged from -0.59 to $-1.63(S E=.20)$ and skewness for guilt ranged from -.31 to -2.30 $(S E=.20)$. This suggests that people may think that perpetrators' feelings of shame and guilt are quite intense. A series of $2 \times 2$ repeated measures ANOVAs was conducted to determine whether causal attributions influence perceived likelihood of shame and guilt and whether perceived emotional response varied as a function of whether only the actor was injured (intrapersonal consequence) or both the actor and others faced injured (interpersonal consequences). The first ANOVA tested whether unstable-controllable attributions would elicit greater levels of perceived guilt compared to shame, and whether the type of transgression (interpersonal or intrapersonal) would influence perceptions of guilt and shame. In the unstable-controllable scenarios there was 
a significant main effect of emotion. As expected, participants perceived significantly greater levels of guilt $(M=4.33, S E=.04)$ compared shame $(M=3.94, S E=.06), F(1,141)=84.80, p<$ $.001, \eta_{\mathrm{p} 2}=.376$. There was also a significant main effect of whether the scenario was interpersonal or intrapersonal. Participants perceived greater levels of shame and guilt in interpersonal scenarios $(M=4.57, S E=.05)$ compared to the intrapersonal scenarios $(M=3.70$, $S E=.06), F(1,141)=188.03, p<.001, \eta_{\mathrm{p} 2}=.571$. There was no statistically significant interaction between emotion and type of scenario, $F(1,141)=.36, p=.55, \eta_{\mathrm{p} 2}=.003$ (Figure 5).

\section{Figure 5}

Interaction between emotion and type of transgression in unstable-controllable scenarios (Study 3)

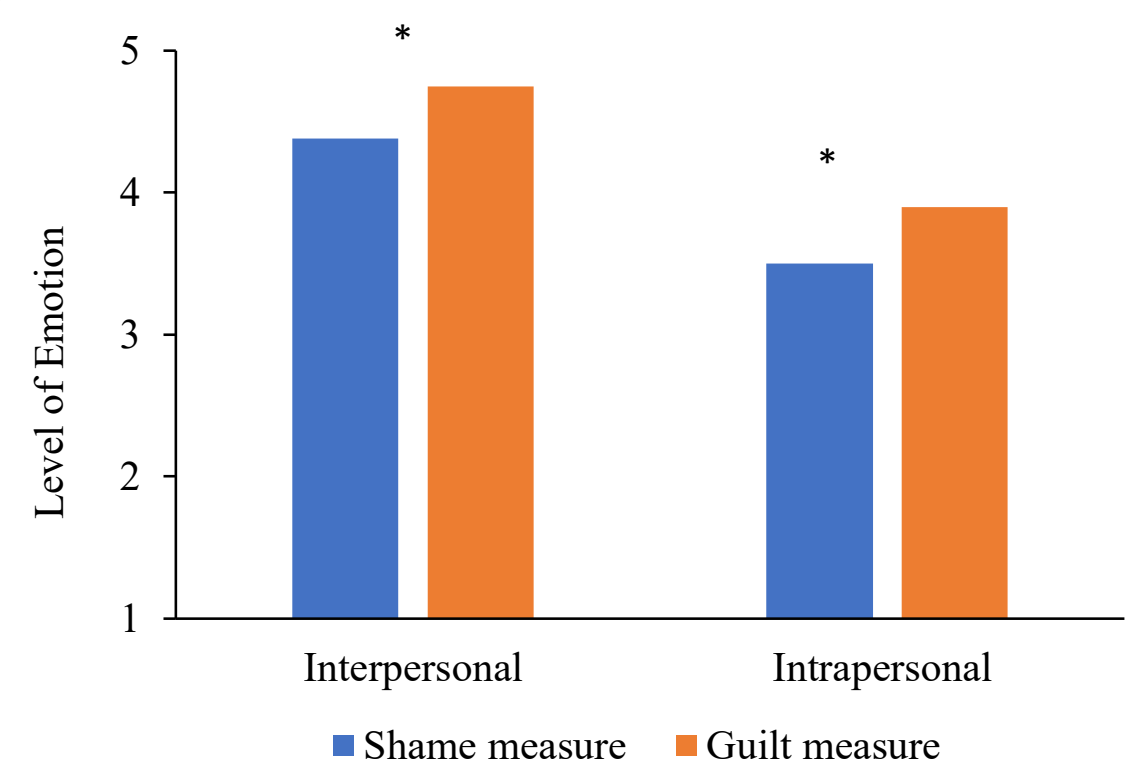

Note. $N=142, * p<.001$.

The second ANOVA tested whether stable-uncontrollable attributions would elicit greater levels of perceived shame compared to guilt, and whether the type of transgression (interpersonal or intrapersonal) would influence perceptions of shame and guilt. In the stableuncontrollable scenarios there was a significant main effect of emotion. Contrary to my expectation, participants again perceived significantly greater levels of guilt $(M=3.91, S E=.06)$ 
compared shame $(M=3.65, S E=.07), F(1,141)=39.90, p<.001, \eta_{\mathrm{p} 2}=.221$. There was also a significant main effect of whether the scenario was interpersonal or intrapersonal. Participants again perceived greater levels of shame and guilt in interpersonal scenarios $(M=4.22, S E=.07)$ compared to intrapersonal scenarios $(M=3.34, S E=.07), F(1,141)=149.64, p<.001, \eta_{\mathrm{p} 2}=$ .515. These main effects were qualified by a two way interaction between emotion and type of transgression, $F(1,141)=5.72, p=.018, \eta_{\mathrm{p} 2}=.039$. Participants perceived a greater difference between levels of guilt $(M=4.39, S E=.07)$ and shame $(M=4.05, S E=.08)$ when the stableuncontrollable scenario was interpersonal, $F(1,141)=47.97, p<.001, \eta_{\mathrm{p} 2}=.254$. Participants perceived a smaller, yet still statistically significant, difference between guilt $(M=3.43, S E=$ $.08)$ and shame $(M=3.26, S E=.08)$ in the intrapersonal scenarios, $F(1,141)=9.71, p=.002, \eta_{\mathrm{p} 2}$ $=.064$ (Figure 6$)$.

\section{Figure 6}

Interaction between emotion and type of transgression in stable-uncontrollable scenarios (Study 3)

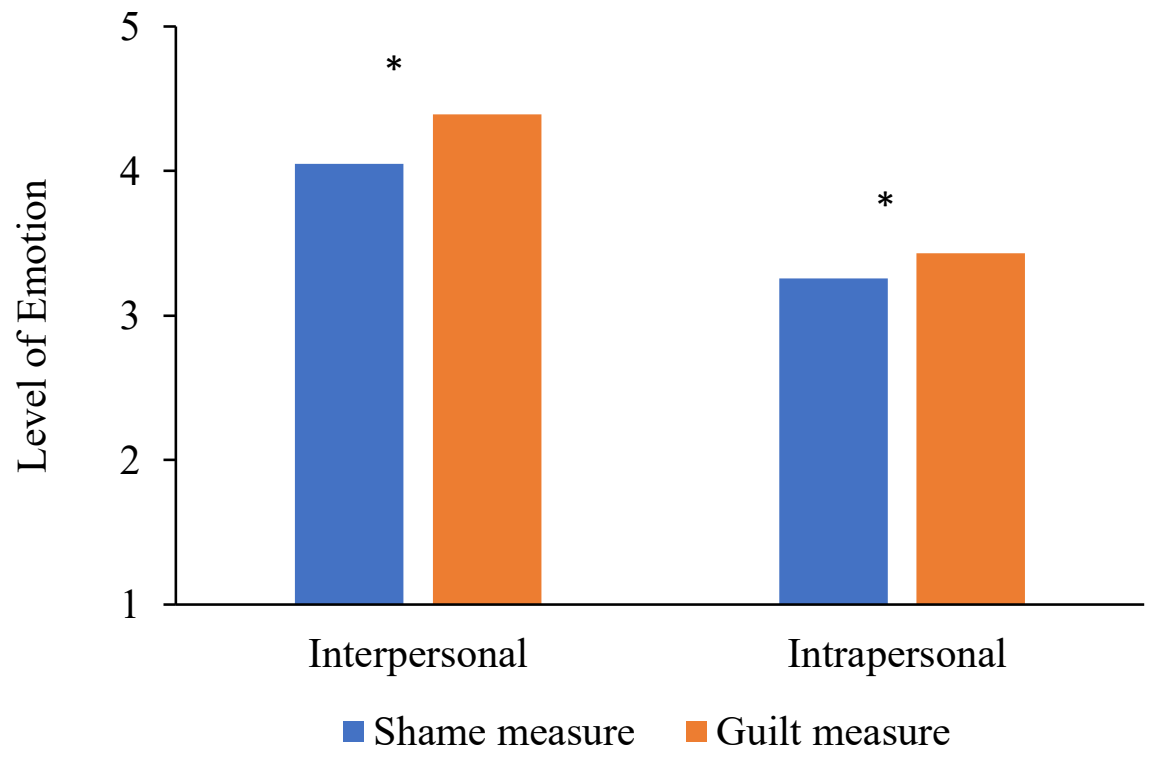

Note. $N=142,{ }^{*} p<.01$. 
Ratings of perceived likelihood of forgiveness seeking were also highly negatively skewed. Skewness was -1.23 and -1.81 in the stable-uncontrollable and unstable-controllable scenarios, respectively $(S E=.20)$, suggesting that most people strongly agree that actors would seek forgiveness. To explore whether participants perceived that individuals would be more likely to seek forgiveness from others when interpersonal scenarios were unstable and controllable compared to stable and uncontrollable, a paired-samples $t$-test was conducted. Although there was a trend suggesting that participants perceived a greater likelihood of forgiveness seeking following unstable-controllable scenarios (presumed guilt inducing attributions; $M=4.54, S D=0.82$ ) compared to stable-uncontrollable scenarios (presumed shame inducing attributions; $M=4.43, S D=0.82), t(114)=-1.35, p=.18$, this difference was not statistically significant.

A 2x2 repeated measures ANOVA was conducted to explore whether participants perceived that actors would be more likely to forgive themselves following presumed shame inducing attributions (stable-uncontrollable) or presumed guilt inducing attributions (unstablecontrollable) and whether perceived likelihood of self-forgiveness varied as a function of whether only the actor was injured (intrapersonal consequence) or both the actor and others faced injuries (interpersonal consequences). There was a significant main effect of presumed emotion. Participants reported a greater perceived likelihood of self-forgiveness in the stableuncontrollable scenario $(M=3.24, S E=.08)$ compared to the unstable-controllable scenario, $(M$ $=3.01, S E=.07), F(1,120)=12.48, p=.001, \eta_{\mathrm{p} 2}=.094$. There was also a significant main effect of whether the scenario was interpersonal or intrapersonal. Participants perceived a greater likelihood of self-forgiveness in the intrapersonal scenarios (involved injuries to the self; $M=$ $3.50, S E=.07$ ) compared to the interpersonal scenarios (included injuries to others; $M=2.76, S E$ 
$=.08), F(1,120)=87.25, p<.001, \eta_{\mathrm{p} 2}=.412$. There was no statistically significant interaction between presumed emotion and type of scenario, $F(1,120)=.78, p=.38, \eta_{\mathrm{p} 2}=.006$ (Figure 7).

\section{Figure 7}

Interaction between causal attributions and type of transgression (Study 3)

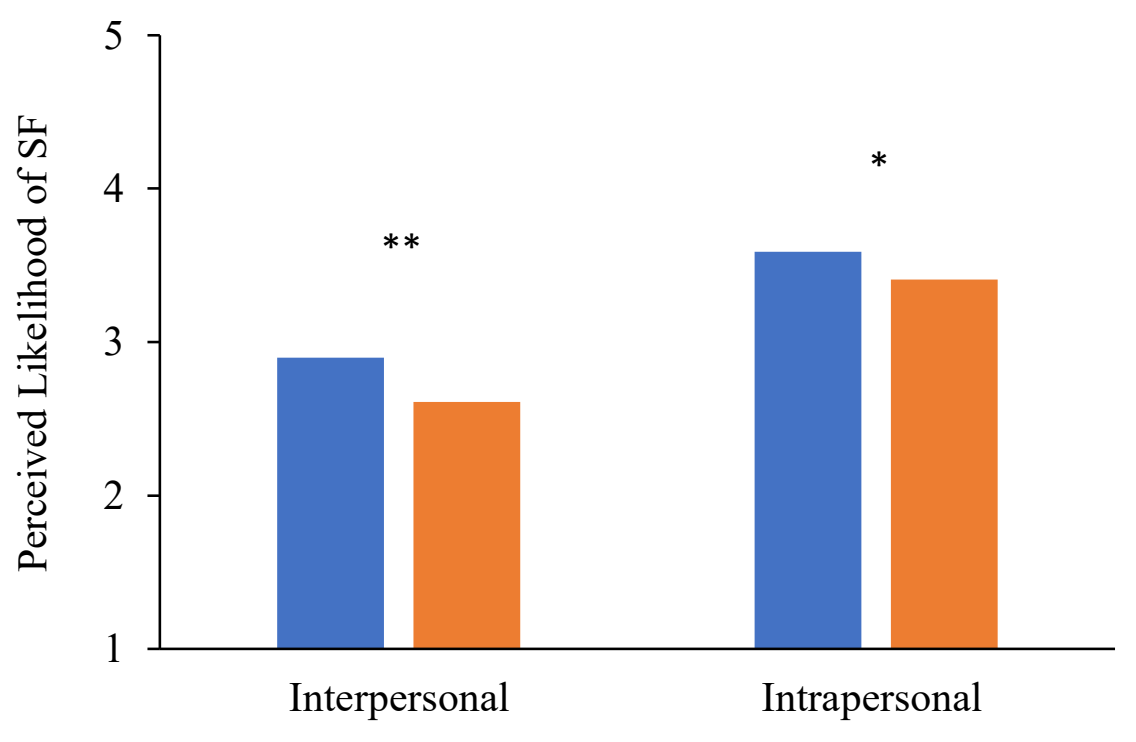

- Presumed Shame (stable-uncontrollable scenarios)

- Presumed Guilt (unstable-controllable scenarios)

Note: $N=121,{ }^{* *} p<.01,{ }^{*} p<.05$.

In order to assess whether levels of perceived shame and guilt were associated with forgiveness seeking and self-forgiveness, bivariate correlations (Tables 4 and 5) were conducted. Shame and guilt were consistently highly correlated $(r=.70$ to $r=.78)$ suggesting the presence of multicollinearity. Perceived likelihood of forgiveness seeking was significantly correlated with shame $(r=.49)$ and guilt $(r=.51)$ in the stable-uncontrollable scenario and significantly correlated with shame $(r=.26)$ and guilt $(r=.25)$ in the unstable-controllable scenario. In the interpersonal scenarios perceived likelihood of self-forgiveness was inversely associated with shame ( $r=-.28$ and $r=-.31)$ and guilt $(r=-.31$ and $r=-.37)$. In the intrapersonal scenarios 
perceived likelihood of self-forgiveness was inversely associated with shame $(r=-.24$ and $r=$ $.22)$ in both scenarios, but only associated with guilt $(r=-.18)$ in the stable-uncontrollable scenario, not the in unstable-controllable scenario $(r=-.10)$. To test whether guilt predicted perceived likelihood of forgiveness seeking from others over and above perceived shame a series of regressions was conducted. In the stable-uncontrollable scenario, both measures of guilt ( $\beta=$ $.32, p=.008)$ and shame $(\beta=.23, p=.033)$ significantly predicted seeking forgiveness from others, $R_{2}=.28, F(2,139)=26.93, p<.001$. However, although the covariance of shame and guilt significantly predicted perceived likelihood of forgiveness seeking in the unstablecontrollable scenario, neither measures of guilt $(\beta=.24, p=.26)$ nor shame $(\beta=.18, p=.15)$ significantly predicted likelihood of forgiveness seeking over and above one another, $R_{2}=.08$, $F(2,139)=5.71, p=.004$. It is likely that, because shame and guilt are highly related, the small marginal contributions of shame and guilt make it almost impossible to detect the unique effects of each of these variables on forgiveness seeking.

Similarly, although the covariance significantly predicted perceived self-forgiveness in the stable-uncontrollable scenarios, neither guilt $(\beta=-.32, p=.07)$ nor shame $(\beta=-.13, p=.40)$ uniquely predicted self-forgiveness in the interpersonal scenario, $R_{2}=.10, F(2,133)=7.46, p=$ .001 , and neither guilt $(\beta=-.03, p=.83)$ nor shame $(\beta=-.26, p=.059)$ uniquely predicted selfforgiveness in the intrapersonal scenario, $R_{2}=.06, F(2,135)=4.14, p=.018$. This is likely also explained by the shared variance in the predictor variables (shame and guilt). In the unstablecontrollable-interpersonal scenario, only the measure of guilt $(\beta=-.734, p=.008)$, but not the measure of shame ( $\beta=-.13, p=.39)$ significantly predicted self-forgiveness, $R_{2}=.14, F(2,126)$ $=10.55, p<.001$. In the unstable-controllable-intrapersonal scenario, only the measure of shame 
$(\beta=-.30, p=.020)$, but not the measure of guilt $(\beta=.10, p=.47)$ significantly predicted selfforgiveness, $R_{2}=.05, F(2,130)=3.41, p=.036$.

\section{Table 4}

Bivariate correlations between shame, guilt, forgiveness seeking, and self-forgiveness in interpersonal scenarios

\begin{tabular}{lcccc}
\hline & 1 & 2 & 3 & 4 \\
\hline 1. Shame & 1 & $.78^{* *}$ & $.49^{* *}$ & $-.28^{* *}$ \\
$\begin{array}{l}\text { 2.Guilt } \\
\text { 3.Forgiveness }\end{array}$ & $.21^{* * *}$ & 1 & $.51^{* *}$ & $-.31^{* *}$ \\
$\begin{array}{l}\text { seeking } \\
\text { 4.Self-forgiveness }\end{array}$ & $-.31^{* *}$ & $.25^{* *}$ & 1 & -.06 \\
\end{tabular}

Note. Correlations in the top triangle of the matrix are for the stable and uncontrollable scenario and correlations in the bottom triangle are for the unstable and controllable scenario. ${ }^{*} \mathrm{p}<.01$ (two-tailed), $N=129-142$.

\section{Table 5}

Bivariate correlations between shame, guilt, and self-forgiveness in intrapersonal scenarios

\begin{tabular}{|c|c|c|c|}
\hline & 1 & 2 & 3 \\
\hline 1.Shame & 1 & $.72 * *$ & $-.24 * *$ \\
\hline 2.Guilt & $.70 * *$ & 1 & $-.18 *$ \\
\hline $\begin{array}{l}\text { 3.Self- } \\
\text { forgiveness }\end{array}$ & $-.22 *$ & -.10 & 1 \\
\hline
\end{tabular}

Note. Correlations in the top triangle of the matrix are for the stable and uncontrollable scenario and correlations in the bottom triangle are for the unstable and controllable scenario. ${ }^{*} \mathrm{p}<.05$, $* * \mathrm{p}<.01$ (two-tailed), $N=133-142$.

\section{Discussion}


The first purpose of Study 3 was to test whether unique combinations of causal attributions differentially elicit perceived shame and guilt in both interpersonal and intrapersonal scenarios. It was hypothesized that when scenarios were unstable and controllable, participants would expect a greater likelihood of guilt (compared to shame) from the actors in the scenario. However, when scenarios were stable and uncontrollable, it was hypothesized that participants would expect a greater likelihood of shame compared to guilt. Participants perceived a greater level of guilt, compared to shame, in both the unstable-controllable scenarios (as hypothesized) as well as the stable-uncontrollable scenarios (contrary to my hypothesis). This effect was consistent across both interpersonal and intrapersonal scenarios.

These results suggest people believed that, irrespective of the causes tested and whether or not there were other victims involved, crashing one's car elicits more guilt than shame. These results do suggest that there is some distinction between shame and guilt, but participants were not distinguishing between shame and guilt as expected by Weiner's model (1985). However, it remains possible that the scenarios used in the current study did not accurately manipulate the causal dimensions. For instance, participants may have believed that a car crash caused by a chronic inability to pay attention is controllable, rather than uncontrollable, as the initial decision to drive, despite issues with attention, is a deliberate, controllable, one. A perceived controllable causal attribution, rather than an uncontrollable causal attribution, in this scenario would help explain why participants did not expect actors to feel more shame than guilt. Although guilt was consistently greater than shame across all scenarios, participants still perceived that the actors would feel shame as well. Participants may believe that shame and guilt co-occur to some extent, such that feelings of guilt promote simultaneous or subsequent feelings of shame or vice versa. 
In both stable-uncontrollable and unstable-controllable scenarios, participants expected a greater level of shame and guilt when the scenario resulted in injuries to both the self and others (interpersonal) rather than just to the self (intrapersonal). These findings suggest that individuals expect perpetrators to feel a greater degree of shame and guilt when their actions have hurt others whereas individuals expect perpetrators to feel less shame and guilt when it is evident that their actions have only hurt themselves. This is consistent with previous research which suggests that both shame and guilt are interpersonal emotions - that is, these emotions often arise in situations that involve others. Individuals' descriptions of shame and guilt-inducing situations frequently involve either concerns about one's effect on others or concerns with others' evaluations on the self (Tangney, 1992).

Examining the link between causal attributions and emotions was a precursor to the main purpose of the current study. The main purpose of this study was to examine how shame and guilt, as well as shame and guilt inducing attributions, relate to perceived likelihood of forgiveness seeking and self-forgiveness. It was expected that guilt inducing attributions and guilt would elicit a greater perceived likelihood that actors would seek forgiveness from their victims compared to shame inducing attributions and shame. Although there was a trend towards more perceived forgiveness seeking in the presumed guilt inducing scenario (unstablecontrollable attributions) compared to the presumed shame inducing scenario (stableuncontrollable attributions), this was not statistically significant. It is possible that presumed guilt- and shame-inducing attributions (according to Weiner) do not differentially influence perceived likelihood of seeking forgiveness from one's victims. This null result may also be attributable to the manipulation of causal attributions. Participants may not have interpreted the 
attributions as hoped, which is a precursor to testing this association between causal attributions and forgiveness seeking.

Shame and guilt both predicted forgiveness seeking over and above one another, but only in the stable-uncontrollable scenarios. In the unstable-controllable scenarios, the covariance of shame and guilt predicted forgiveness seeking but shame and guilt did not predict forgiveness seeking over and above one another. It is likely that the perceived similarity between these two emotions made it difficult to determine the effect of each emotion in explaining forgiveness seeking. These results suggest that people believe that feelings of shame and guilt are important motivators of forgiveness seeking, but, because people do not always distinguish between them, whether shame or guilt is more important in predicting forgiveness seeking is unclear. These findings may be inconsistent with past research that has suggested that guilt, more than shame, motivates interpersonal repair following a wrongdoing (Baumeister et al., 1994). One should also keep in mind that forgiveness seeking was measured by asking participants about their perceived desire for forgiveness. Perceived desire for forgiveness might not equate to the likelihood of seeking it for some individuals. Although participants may believe that both shame and guilt elicit the desire for forgiveness, they may not believe that both shame and guilt equally motivate actors to take steps to seek it. Adams and Inesi (2016) did find that lower perceived levels of perpetrator's guilt contribute to lower perceived desire for forgiveness. However, because these researchers did not also examine shame, it is unclear whether the relationship between the desire for forgiveness and shame should differ. Although directly asking participants about their perceived likelihood of forgiveness seeking may have addressed this issue, this wording may have been ambiguous for those without any background knowledge about the meaning of forgiveness seeking. 
The current study also explored whether perceived likelihood of self-forgiveness was differentially associated with shame- and guilt-inducing attributions, the type of transgression (interpersonal or intrapersonal), and perceived shame and guilt. Participants perceived a greater likelihood of self-forgiveness following presumed shame inducing attributions (stableuncontrollable) compared to presumed guilt inducing attributions (unstable-controllable). This may be consistent with findings that suggest that individuals are less likely to forgive themselves when they feel guilt compared to when they feel shame (Hall \& Fincham, 2008). Perceived likelihood of self-forgiveness was greater in scenarios that only involved harm to the self, compared to scenarios that also involved harm to others. This is likely because a transgression that hurts others in addition to the self may carry a larger burden and might be one that makes it more challenging to once again view oneself positively.

I expected that, across all scenarios, the more shame and guilt a person perceived, the less likely he or she would perceive an actor to forgive him or herself. I did find that the more shame and guilt a person perceived, the less likely he or she would be to expect self-forgiveness in three of the four scenarios. When a negative outcome occurred due to something unstable and controllable and the incident did not involve harm to others shame, but not guilt, was negatively associated with perceived self-forgiveness. When examining the unique effects of shame and guilt on self-forgiveness separately across each scenario I found that, in the unstablecontrollable-interpersonal scenario, the more guilt individuals perceived (over and above perceived shame), the less self-forgiveness they expected, whereas in the unstable-controllableintrapersonal, the more shame individuals perceived (over and above perceived guilt), the less self-forgiveness they expected. Although the covariance of shame and guilt influenced one's perceived likelihood of self-forgiveness in the stable-uncontrollable scenarios, shame and guilt 
did not predict likelihood of self-forgiveness over and above one another. This suggests that the potential inconsistencies that exist in the literature on shame, guilt, and forgiveness (i.e., shame should make it harder to forgive the self if shame involves seeing the self as negative vs. findings suggesting that guilt, over and above shame, makes self-forgiveness harder) may be partly explained by different causal attributions and types of transgressions (interpersonal or intrapersonal). According to these results, it appears as though people believe it is harder for others to forgive themselves for a negative outcome that could have been controlled and was caused by something temporary. It is only in these scenarios where shame and guilt differentially predict self-forgiveness. When the cause of an outcome is controllable and unstable (temporary) and the outcome harms only the self, it seems as though people believe shame is the emotion that inhibits one's ability to forgive the self (I am a bad person, how can I forgive myself?). However, when the same negative outcome also harms others, people believe it is guilt, rather than shame, that inhibits one's ability to forgive the self (My bad behavior, my empathy for my victims, and my focus on interpersonal repair is what makes it difficult for me to forgive myself). It is unclear why this differentiation between shame and guilt on perceived self-forgiveness did not exist in the stable-uncontrollable scenarios (which elicited a greater degree of perceived self-forgiveness compared to unstable-controllable scenarios). If a car crash occurs due to a stable-uncontrollable cause (e.g., chronic inability to pay attention), perhaps perceived self-forgiveness is influenced more by the causal attributions (this happened because this is just who I am and who I am always going to be), rather than shame or guilt. If a car crash occurs due to the choice to text and drive (unstable-controllable), perhaps perceived self-forgiveness is less influenced by causal attributions and more influenced by perceived emotions (differently for interpersonal and intrapersonal transgressions). It is also possible that issues of multicollinearity prevented me 
from detecting any unique effects of shame and guilt on perceived likelihood of self-forgiveness in the stable-uncontrollable scenarios.

\section{General Discussion}

In a social world where transgressions are inevitable, people are frequently exposed to stories of harm, whether through social media, traditional news outlets, or word of mouth. Psychology research on transgressions has understandably focused much attention on the experience of victims. However, less work has explored the experience of the perpetrator. Better understanding how observers, who are not directly affected by transgressions but have been exposed to minimal information about the situation, make sense of a perpetrator's experience might have implications for conflict resolution, for law and punishment, and for day to day interactions. Do people believe that perpetrators feel shame and guilt and if so, do people make a distinction between these emotions? Do people believe that perpetrators are concerned with seeking forgiveness from others and forgiving themselves and if so, is it something about the transgression or the perceived emotions that influence these perceptions? These are the questions that the current studies attempted to address.

\section{Shame and guilt distinction}

Most people do believe that a perpetrator will feel some extent of both shame and guilt, so the question becomes whether there is a distinction and what this distinction is. The literature on shame and guilt appears to be inconclusive. People often experience difficulty defining shame and guilt (Lindsay-Hartz, 1984) and, although theory has suggested that shame and guilt differ, there are a number of different theories about where exactly this distinction may lie. The current study adopted Weiner's (1985) causal attribution theory to test whether shame and guilt differ based on the causes that lead to a negative outcome. People perceived higher levels of shame, 
compared to guilt, when poor academic failure was attributable to a stable, uncontrollable cause and only harmed the self (in studies one and two). People perceived higher levels of guilt, compared to shame, when poor academic performance was attributable to an unstable and controllable cause and included harm to others (in study 2) and perceived higher levels of guilt, compared to shame, following a car crash that was attributable to either stable-uncontrollable or unstable-controllable causes and that involved harm to the self or included harm to others (in study 3).

Across many of the scenarios used in these studies, people were making a distinction between shame and guilt. However, these results either suggest that there may have been some ambiguity in the manipulation of causal attributions, or that causal attributions do not (consistently) differentiate perceptions of shame and guilt. Tangney (1992) discusses how past research has suggested that guilt is often induced by moral transgressions, especially those that include harm to others, whereas shame seems to be induced by a broader range of situations shame can arise following moral transgressions but also nonmoral transgressions. Tangney (1992) found that individuals reported nonmoral incidents, such as failure in performance situations, as shame inducing but rarely associated such situations with feelings of guilt. It is possible that crashing one's car or choosing to perform poorly and letting others down as a result are interpreted as moral transgressions, which might explain why guilt was rated more highly than shame. Performing poorly purely based on a lack of ability likely was not interpreted as a moral transgression, potentially explaining why it was associated more with feelings of shame than guilt.

Although most of the time people expected that interpersonal scenarios would elicit greater levels of shame and guilt compared to intrapersonal scenarios, this was not the case for 
the unstable and controllable scenarios in the first two studies. This inconsistency in the first two studies may be because, unlike the scenarios in the third study, the scenarios in the first two studies were not held constant (i.e., more than just the victims involved differed). Interpersonal scenarios (those that include harm to others in addition to the self) eliciting greater shame and guilt compared to intrapersonal scenarios (those that do not harm others) is consistent with previous work suggesting that both shame and guilt are interpersonal emotions (Tangney, 1992).

An important consideration when attempting to understand the distinction between emotions is that emotions present a lot of variability and that interpreting emotions may be largely subjective. Barrett (2017), who understands emotions in terms of emotion categories and instances of emotions, suggests that there is no single distinction between two emotions because no emotion has a single 'fingerprint'. She discusses how perceptions exist within the perceiver and discusses how these perceptions can depend on a number of factors that live beyond the emotion itself. Perceptions can be influenced by words as words allow people to form emotion concepts, which is a precursor to experiencing or perceiving the emotion. Emotional granularity, which refers to the number of emotion concepts one possesses, also influences emotion perception. For instance, someone with low emotion granularity may understand shame and guilt as interchangeable - belonging to one emotion concept - whereas those with high emotion granularity may be better able to use words to distinguish between different feelings. In the Greek language, there are two distinct words for guilt - one for minor infractions and one for more serious transgressions. Thus, one might expect the concept of guilt to be interpreted differently by Greek and English speakers. Having more emotion words contributes to more emotion granularity and a better understanding of the distinction between emotions (Barrett, 2017). Considering the variability in emotion perception is important not only because it may 
help to explain some of the inconsistencies across these three studies and some of the nonsignificant results, but also because it suggests that although some may understand shame and guilt in one way, there are likely other ways in which these emotions are understood. The different theories that have been proposed over the years on shame and guilt and their similarities and differences may all hold some truth for some people, but it is unlikely that there is a single best answer. Despite inevitable variation in emotion perception and, although Weiner's (1985) causal attribution theory is just one approach to understanding the distinction between shame and guilt, understanding trends in emotion perception provides the opportunity to study perceived behavioural outcomes, such as forgiveness seeking and self-forgiveness, and provides the opportunity to better understand law, and conflict resolution.

\section{Forgiveness Seeking}

The current studies suggested that people did not expect that perpetrators would be more likely to seek forgiveness from victims following unstable-controllable causal attributions (presumed guilt inducing) compared to stable-uncontrollable causal attributions (presumed shame inducing) as expected. It is possible that the combinations of causal attributions tested in this study do not play a large role in determining peoples' perceptions about a perpetrator's likelihood of seeking forgiveness following a transgression.

Furthermore, people in my studies expected that feelings of guilt would motivate a perpetrator to seek forgiveness from those who were harmed, over and above feelings of shame, but only when the perpetrator's actions were stable and uncontrollable. When a perpetrator's actions were unstable and controllable, people in my studies did expect that shame and guilt would motivate forgiveness seeking, but they did not make a distinction between the two emotions. In the third study, people also expected that shame would promote forgiveness seeking 
from others but only when the perpetrator's actions were stable and uncontrollable. Despite the literature suggesting that guilt, more than shame, promotes interpersonal repair, individuals may not understand guilt and shame in these ways; individuals might believe that both shame and guilt play some role in determining how likely one is to seek forgiveness for a wrongdoing.

\section{Self-forgiveness}

When individuals believe that perpetrators desire at least some degree of self-forgiveness following the commitment of a wrongdoing, they believe that self-forgiveness is easier when the wrongdoing only harmed the self and did not include harm to other people. Individuals also believe that self-forgiveness is easier when a negative outcome is caused by something that is stable and uncontrollable (a shame inducing attribution) and harder when the same negative outcome is caused by something unstable and controllable (a guilt inducing attribution). It is only in the scenarios where people expect self-forgiveness to be more difficult that they also expect that shame and guilt differentially influence the ability to forgive the self. It is feelings of shame that people believe hinders self-forgiveness when only the self is harmed, but feelings of guilt that people believe hinders self-forgiveness when the harm extends to others. The selfforgiveness literature thus far has not been clear with regards to whether it is shame or guilt that prevents one from forgiving the self. This research suggests that it may not be such a straightforward answer. It may be important to consider variables such as causal attributions and whether other victims are involved to understand the relationship between emotions and selfforgiveness.

Although this current research suggests that people sometimes do expect different levels of shame and guilt from an individual who committed a wrongdoing, people do not consistently distinguish between shame and guilt in all the ways I expected them to. One speculation might 
be that understanding relationships between concepts such as shame, guilt, and forgiveness requires the consideration of new dimensions. For instance, whereas a stable and uncontrollable causal attribution does sometimes elicit more perceived shame than guilt (consistent with Weiner's 1985 model), this appears only to hold true when nobody else is harmed, this 'effect' seems to disappear when other victims are introduced to the scenario. Furthermore, the question might not simply be whether perceived shame or perceived guilt makes people believe it is harder to forgive the self, but rather, when it is shame and when it is guilt that make selfforgiveness more difficult. There might be specific situations where shame is expected to inhibit one's ability to forgive the self (i.e., following an event that occurred due to unstable and controllable causes and resulted in intrapersonal consequences), and where guilt is expected to inhibit one's ability to forgive the self (i.e., following an event that occurred due to unstable and controllable causes and resulted in interpersonal consequences). Although causal attributions and the type of transgression are two additional variables worth considering, future work may wish to consider others, such as intentionality and level of harm.

Another possible explanation for these results is that people do not understand the difference between shame and guilt. Although some research has found that college students do have some implicit understanding of the difference between shame and guilt (Tangney, 1992), individuals often struggle with defining shame and guilt and some people question whether there is any difference between the two emotions (Lindsay-Hartz, 1984). If people do have a difficult time understanding the difference between shame and guilt, this would help to explain some of the inconsistencies across my three studies and some of the non-significant results. Furthermore, it is possible that other emotions occur simultaneously with shame and guilt and that they interact with shame and guilt to elicit forgiveness seeking and self-forgiveness. If participants in 
my studies expect that shame and/or guilt co-occur with other emotions (e.g., sadness), the expectation of these other emotions may have influenced their perceptions on forgiveness seeking and self-forgiveness.

Another consideration is that emotions, such as shame and guilt, may not have universal unique antecedents and unique behavioural outcomes. Emotions may be convoluted - muddled by variation. The labelling of emotions may lie in the eye of the beholder and variation in the perception of shame and guilt concepts would suggest variation in perceived antecedents of shame and guilt (causal attributions) and behavioural outcomes (forgiveness seeking and selfforgiveness) as well. As stated by Barrett (2017), "we construct our own emotional experiences and our perceptions of others' emotions, on the spot, as needed, through a complex interplay of systems. Human beings are not at the mercy of mythical emotion circuits buried deep within animalistic parts of our highly evolved brain: we are architects of our own experience" (p. 40).

Although emotions may carry significant variability, how people make sense of a perpetrator's experience does have implications for the criminal justice system as well as day to day interactions. Judgments about a perpetrator are influenced by the emotions that he or she displays. People typically have less harsh judgements towards perpetrators who appear upset and remorseful about a transgression (Robinson, Smith-Lovin, \& Tsoudis, 1994). However, if it is true that one's demeanor cannot accurately reveal emotion (Barrett, 2017), it may be important to turn to other strategies that people use to understand how people are feeling, such as the cause of the crime or wrongdoing. Understanding how people make sense of a perpetrators experience (emotions they are likely feeling and likelihood of future behaviours such as seeking forgiveness and self-forgiveness) might not only shine light on how judges make decisions about punishment. It is also reasonable to assume that day to day transgressions function similarly, 
such that people likely judge perpetrators more leniently if they believe the perpetrator feels badly for his or her wrongdoing. Ysseldyk and Wohl (2012) found that people are more likely to forgive perpetrators who show greater levels of remorse. Thus, the way one understands a perpetrator's experience likely influences decisions on legal punishment and future interactions with the perpetrator. The current research sought to test whether and how people think about a perpetrator's experience following minor infractions (e.g., poor academic performance) and more serious transgressions (e.g., texting and driving). Future work is encouraged to implement the current discussion in future work on jury decision making and conflict resolution strategies.

\section{Strengths and limitations}

The strengths of this study include the manipulation of causal attributions (stability and controllability) and the type of transgression (interpersonal or intrapersonal) and the use of different scenarios and two different methods of measuring shame and guilt across the three studies. Sample three also had a large sample size for a within subjects design that allowed for powerful analyses. In terms of limitations, it is possible that some of the scenarios used in the current studies were ambiguous for some participants. It is unknown whether all the scenarios were interpreted as I hoped. However, I attempted to make the manipulations of controllability and stability and whether or not there were any other victims involved as obvious as possible in all scenarios. Any potential ambiguity would not have influenced one of my main research questions - whether and how perceived emotion influences perceived forgiveness seeking and self-forgiveness. There may also be some limitations of using vignettes. For instance, it is possible that a hypothetical scenario does not elicit the same level or accuracy of emotion compared to a true, experienced situation. However, hypothetical scenario methodologies allow for experimental manipulation, which was an important component of the current studies, and 
there has been research suggesting that findings from scenario methodologies are consistent with findings from more realistic approaches (Robinson \& Clore, 2001). Furthermore, the strong correlation between shame and guilt suggests the presence of multicollinearity, which made it challenging to detect the unique effects of shame and guilt on perceived forgiveness seeking and self-forgiveness. I also measured one of my variables of interest, forgiveness seeking, through asking participants about the extent to which they believed the actor in the scenario would desire forgiveness from their victims. Despite realizing that one's desire for forgiveness and engaging in behaviours to seek forgiveness may differ, I was unsure whether participants would have a conceptual understanding of 'seeking forgiveness' and therefore desire for forgiveness was the wording used instead. Choosing to measure forgiveness seeking through more intelligible terms (desire) allowed me to be more confident that the concept was understood as intended by participants. Furthermore, despite using the term 'desire for forgiveness' rather than 'seek forgiveness', participants may have assumed that one's desire for forgiveness necessitates the seeking of forgiveness. Future research may wish to test whether this is the case. Lastly, this research was limited to what observers believe that perpetrators feel and did not test what perpetrators themselves do feel following the commitment of a transgression.

\section{Conclusion and Future Directions}

Transgressions are an ordinary part of life. Although transgressions typically involve both a perpetrator and victim(s), research has focused most of its attention on understanding the experience of victims. Despite the importance of such research, understanding the experience of the perpetrator and the ways in which individuals make sense of the perpetrator's experience provides a more thorough understanding of the psychology of transgressions. This research suggests that observers typically believe that perpetrators feel high levels of shame and guilt 
following a transgression and people are sometimes able to distinguish between perpetrators' instances of shame and guilt. Perceptions on shame and guilt have implications for whether people believe a perpetrator will desire forgiveness from his or her victims and for whether people believe that a perpetrator will forgive himself or herself. The presence or absence of victims also seems to help guide people's perceptions of shame and guilt and self-forgiveness, such that people expect a perpetrator to feel more shame and guilt and forgive himself or herself less when victims are involved compared to when victims are absent. Causal attributions may also aid people in their perceptions about a perpetrator's shame and guilt and in their perceptions about a perpetrator's ability to forgive himself or herself following a transgression. Future research should explore whether the effects of the manipulations tested in this thesis are attributable merely to either the controllability or stability dimension, or whether the combination of these causal dimensions are required to elicit the findings from these studies. Although Tracy and Robins (2006) found that both the manipulation of controllability and stability influenced shame and guilt, they found that the controllability manipulation had a larger effect on the distinction between shame and guilt, compared to the stability dimension. Thus, future work may wish to consider assessing the unique effects of controllability and stability on observers' perceptions about a perpetrator's feelings. Future work should also explore how perceptions of emotion and forgiveness influence the ways in which people engage with and judge a perpetrator, and how these findings can be integrated into existing conflict resolution strategies. 


\section{References}

Adams, G. S., \& Inesi, M. E. (2016). Impediments to forgiveness: Victim and transgressor attributions of intent and guilt. Journal of Personality and Social Psychology, 111(6), 866-881.

Barrett, L. F. (2017). How emotions are made: The secret life of the brain. Houghton Mifflin Harcourt.

Baumeister, R. F., Stillwell, A. M., \& Heatherton, T. F. (1994). Guilt: An interpersonal approach. Psychological Bulletin, 115, 243-267.

Baumeister, R. F., Stillwell, A. M., \& Heatherton, T. F. (1995). Personal Narratives about guilt: Role in action control and interpersonal relationships. Basic and Applied Social Psychology, 17, 173-198.

Coates, D. (1977). The correlations of forgiveness of self, forgiveness of others, and hostility, depression, anxiety, self-esteem, life adaptation, and religiosity among female victims of domestic abuse. Dissertation Abstracts International, 58(5), 2667B. (UMI No. 9734479).

Covington, M. V., \& Omelich, C. L. (1984). An empirical examination of Weiner's Critique of Attribution Research. Journal of Educational Psychology, 76(5), 1214-1225.

Enright, R. D., \& The Human Development Study Group (1996). Counseling within the forgiveness triad: On forgiving, receiving forgiveness, and self-forgiveness. Counseling and Values, 40, 107-126.

Gold, G. J., \& Weiner, B. (2000). Remorse, confession, group identity, and expectancies about repeating a transgression. Basic and Applied Social Psychology, 22, 291-300. 
Hall, J. H., \& Fincham, F. D. (2008). The Temporal Course of Self-Forgiveness. Journal of Social and Clinical Psychology, 27(2), 174-202. https://doi.org/10.1521/jscp.2008.27.2.174

Hoffman, M. L. (1982). Development of prosocial motivation: Empathy and guilt. In N. Eisenberg (Ed.), The development of prosocial behavior (pp. 281-313). San Diego, CA: Academic Press.

Hudley, C. A. (1992). Attributions for pride, anger, and guilt among incarcerated adolescents. Criminal Justice and Behavior, 19, 189-205.

Jagacinski, C. M., \& Nicholls, J. G. (1984). Conceptions of ability and related affects in task involvement and ego involvement. Journal of Educational Psychology, 76(5), 909-919.

Kuppens, P., Van Mechlen, I., Smits, D. J. M., \& De Boek, P. (2003). The appraisal basis of anger: Specificity, necessity, and sufficiency of components. Emotion, 3, 254-269.

Leach, M. M., \& Lark, R. (2004). Does spirituality add to personality in the study of trait forgiveness? Personality and Individual Differences, 37, 147-156.

Lewis, H. B. (1971). Shame and guilt in neurosis. New York: International Universities Press.

Lindsay-Hartz, J. (1984). Contrasting experiences of shame and guilt. American Behavioral Scientist, 27(6), 698-704.

Maltby, J., Macaskill, A., \& Day, L. (2001). Failure to forgive self and others: A replication and extension of the relationship between forgiveness, personality, social desirability, and general health. Personality and Individual Differences, 30, 881-885.

Marschall, D. Saftner, J., \& Tangney, J. P. (1994). The State Shame and Guilt Scale. George Mason University, Fairfax, VA. 
Mauger, P. A., Perry, J. E., Freeman, T., Grove, D. C., McBride, A. G., \& McKinney, K. E. (1992). The measurement of forgiveness: Preliminary research. Journal of Psychology and Christianity, 11, 170-180.

McCullough, M. E., Rachal, K. C., Sandage, S. J., Worthington, E. L., Jr., Brown, S. W., \& Hight, T. L. (1998). Interpersonal forgiving In close relationships: II. Theoretical elaboration and measurement. Journal of Personality and Social Psychology, 75, 15861603.

Niedenthal, P. M., Tangney, J. P., \& Gavanski, I. (1994). “If only I weren’t” versus “if only I hadn't”: Distinguishing shame and guilt in counterfactual thinking. Journal of Personality and Social Psychology, 67(4), 585-595.

Philips, T., Cooper, B., \& Tillinger, E. (Producers), Philips, T. (Director). (2019). Joker [Motion Picture]. United States: Warner Bros.

Riek, B. M. (2010). Transgressions, Guilt, and Forgiveness: A Model of Seeking Forgiveness. Journal of Psychology and Theology, 38(4), 246-254. https://doi.org/10.1177/009164711003800402

Riek, B. M., Luna, L. M. R., \& Schnabelrauch, C. A. (2014). Transgressors' guilt and shame: A longitudinal examination of forgiveness seeking. Journal of Social and Personal Relationships, 31(6), 751-772. https://doi.org/10.1177/0265407513503595

Robinson, D. T., Smith-Lovin, L., \& Tsoudis, O. (1994). Remorse on responses to mock criminal confessions. Social Forces, 73(1), 175-190.

Robinson, M. D., Clore, G. L. (2001). Simulations, scenarios, and emotional appraisal: Testing the convergence of real and imagined reactions to emotional stimuli. Society for Personality and Social Psychology, 27(11), 1520-1532. 
Rosenbaum, R. M. (1973). A dimensional analysis of the perceived causes of success and failure. Dissertation Abstracts International, 33(10-B), 5040.

Sandage, S. J., Worthington, E. L., Hight, T. L., \& Berry, J. W. (2000). Seeking forgiveness: Theoretical context and an initial empirical study. Journal of Psychology and Theology, $28,21-35$.

Schmader, T, \& Lickel, B. (2006). The approach and avoidance function of guilt and shame emotions: Comparing reactions to self-caused and other-caused wrongdoing. Motivation and Emotion, 30(1), 42-55.

Tangney, J. P. (1992). Situational determinants of shame and guilt in young adulthood. Personality and Social Psychology Bulletin, 18, 199-206.

Tangney, J. P. (1995). Recent advances in the empirical study of shame and guilt. American Behavioral Scientist, 38(8), 1132-1145.

Tracy, J. L., \& Robins, R. W. (2006). Appraisal Antecedents of Shame and Guilt: Support for a Theoretical Model. Personality and Social Psychology Bulletin, 32(10), 1339-1351. https://doi.org/10.1177/0146167206290212

Weiner, B. (1979). A theory of motivation for some classroom experiences. Journal of Educational Psychology, 71, 3-25.

Weiner, B. (1985). An attributional theory of achievement motivation and emotion. Psychological Review, 92(4), 548-573.

Weiner, B., Frieze, I. H., Kukla, A., Reed, L., Rest, S., \& Rosenbaum, R. M. (1971). Perceiving the causes of success and failure. Morristown, NJ: General Learning Press.

Wicker, F. W., Payne, G. C., \& Morgan, R. D. (1983). Participant description of guilt and shame. Motivation and Emotion, 7, 25-39. 
Wohl, M. J. A., \& McGrath, A. L. (2007). The perception of time heals all wounds: Temporal distance affects willingness to forgive following an interpersonal transgression. Personality and Social Psychology Bulletin, 33, 1023-1035.

Ysseldyk, R., \& Wohl, M. J. A. (2012). I forgive therefore I'm committed: A longitudinal examination of commitment after a romantic relationship transgression. Canadian Journal of Behavioural Science, 44, 257-263. doi: 10.1037/a0025463. 


\title{
Study 1 Appendices
}

\author{
Appendix A \\ Recruitment Notice: \\ Responses Following Transgressions \\ (30 min or less $/ .25 \%$ course credit)
}

Have you ever thought about how people feel or react after making a mistake? Almost everyone will at some point find themselves in the wrong. We won't ask you to think about your own experiences, but we would love to ask you some questions about how you think people respond to their faults.

You will be asked to read a series of scenarios about wrongdoings committed by others and answer a few questions regarding the feelings and future behaviours of these individuals. We will also ask you a few questions about your own personality. Your participation is completely anonymous. The questionnaire will take approximately 20-30 minutes to complete. You will receive $.25 \%$ credit in compensation for your time.

Your contribution to this research is greatly appreciated!!

This study has received clearance by the Carleton University Research Ethics Board -B (CUREB-B \#110758, expiry: June 30, 2020).

If you have any questions or concerns regarding this study, please contact Elisabeth Xie at elisabethxie@cmail.carleton.ca or the faculty supervisor Dr. Chris Davis at chris.davis@carleton.ca . 


\section{Appendix B \\ Informed Consent:}

The purpose of an informed consent is to ensure that you understand the purpose of the study and the nature of your involvement. The informed consent is intended to provide sufficient information, such that you have the opportunity to determine whether you wish to participate in the study. This study has received clearance by the Carleton University Research Ethics Board $B$ (CUREB-B \#110758, expiry: June 30, 2020).

Study Title: Responses Following Transgressions

Study Personnel Contact: The Principal Investigators of this project are Elisabeth Xie (elisabethxie@cmail.carleton.ca) and Dr. Chris Davis (Faculty, chris.davis@carleton.ca) from the Psychology Department at Carleton University.

Contact in case of concerns: Should you have any ethical concerns about this study then please contact Dr. Natasha Artemeva, Chair of the Carleton University Research Ethics Board-B (613520-2600x4085; ethics@carleton.ca).

Purpose and Task Requirements: The purpose of this study is to gain a better understanding of the way in which people understand and make sense of a perpetrator's experience (i.e., emotions and behavioural responses) after committing a transgression. You will be asked to read a series of scenarios about other people who have acted in ways that are potentially harmful for the self or others and answer a few questions about your opinion on their emotions and forgiveness seeking behaviours. This study will take approximately 20-30 minutes to complete.

Compensation: You will receive a $.25 \%$ course credit for your participation.

Anonymity/Confidentiality: The data collected in this study are anonymous. All data are coded so that your name cannot be associated with any responses that you have provided. Any identifying information associated with your code will be removed from your data once your course credit has been granted. Once the data are anonymous, aggregated data might be shared with trusted colleagues. We collect data through the software Qualtrics, which uses servers with multiple layers of security to protect the privacy of the data (e.g., encrypted websites and password protected storage). The anonymous data will be kept by the primary researchers for 5 years after publication as per American Psychological Association requirements. With your consent to participate in this study you acknowledge this.

Right to Withdraw: Your participation in this study is entirely voluntary. At any point during the study you have the right to not complete any questions or to withdraw with no penalty. If you decide to withdraw from the study you will still receive full compensation for your participation. Withdrawing from the study prior to completion indicates that you do not wish to have your responses included, and data will be deleted if you skip to debriefing to withdraw from the study. Those who do complete the study consent to the use of their responses (in aggregate form) for research and teaching purposes. As responses are anonymous, we cannot remove your data from the study after you submit. 
If you would like to participate in this study, please click the Agree button below. Otherwise, click the Disagree button.

\section{Agree}

Disagree - exit to debriefing 


\section{Appendix C \\ Survey Materials}

Thank you for participating in our study! This study will take approximately 20-30 minutes to complete. Please read each question carefully.

\section{Demographic Questions}

First, we would like to gather some demographic information. All information you provide will be completely confidential and will not be associated in any way with your identity. Please answer the questions below.

1. What is your gender?

Female

Male

Other

2. What is your Age: (in years) 


\section{Scenarios}

[Note to Ethics Reviewers: Participants will be randomly assigned to one of two conditions. In one condition, after reading each scenario, participants will be presented with a rating scale for each of the four emotions (shame, anxiety, guilt and sadness). In the other condition, participants will be presented with a multiple-choice rating scale (i.e., which of the following emotions do you think best describes how [the perpetrator] will feel - select one of the four options). We are doing this so we can evaluate whether participants make a distinction between the emotions of shame and guilt.]

Please carefully read and think about each of the following scenarios before answering each question.

Sam has never put much effort into his appearance (i.e., does not care about what he wears). Sam has been applying for summer jobs with the government and has had a few interviews. Due to Sam's poor choice of clothing, he does not look professional at his interviews. As a result, he does not get hired for any summer job and struggles to pay his bills.

1) Following this experience, to what extent is Sam feeling each of the following emotions:

\begin{tabular}{|c|c|c|c|c|c|}
\hline & 1 & 2 & 3 & 4 & 5 \\
\hline & Not at all & A little & Somewhat & Quite a bit & Very much so \\
\hline Shame & & & & & \\
\hline Anxiety & & & & & \\
\hline Guilt & & & & & \\
\hline Sadness & & & & & \\
\hline
\end{tabular}

OR

1) Following this experience, which of the following emotions do you think best describes how Sam will feel? (select one of the four response options)
a. Shame
b. Anxiety
c. Guilt
d. Sadness

2) Following this experience, to what extent will Sam desire forgiveness from himself?

\begin{tabular}{|c|cc|c|c|}
\hline 1 & 2 & 3 & 4 & 5 \\
\hline Not at all & A little & Somewhat & Quite a bit & Very much so \\
\hline
\end{tabular}


Harper takes out student loans each year in order to pay for her tuition and school related expenses. Harper has always had a very impulsive personality. Every time she receives a student loan payment, she parties like there is no tomorrow, even though she knows that she needs the money. As a result of spending her student loan money on partying with her friends, Harper is unable to make her portion of rent payments and her and her roommates get evicted from their shared apartment.

1) Following this experience, to what extent is Harper feeling each of the following emotions:

\begin{tabular}{|c|c|c|c|c|c|}
\hline & 1 & 2 & 3 & 4 & 5 \\
\hline Shame & Not at all & A little & Somewhat & Quite a bit & Very much so \\
\hline $\begin{array}{c}\text { Anxiety } \\
\text { Guilt }\end{array}$ & & & & & \\
\hline Sadness & & & & & \\
\hline
\end{tabular}

OR

1) Following this experience, which of the following emotions do you think best describes how Harper will feel? (select one of the four response options)
a. Sadness
b. Guilt
c. Anxiety
d. Shame

2) Following this experience, to what extent will Harper desire forgiveness from herself?

\begin{tabular}{|c|c|c|c|c|}
\hline 1 & 2 & 3 & 4 & 5 \\
\hline Not at all & A little & Somewhat & Quite a bit & Very much so \\
\hline
\end{tabular}

3) Following this experience, to what extent will Harper desire forgiveness from her roommates?

\begin{tabular}{|c|c|c|c|}
\hline 1 & 2 & 3 & 4 \\
\hline Not at all & A little & Somewhat & Quite a bit \\
\hline
\end{tabular}


Keegan and his friends signed up for a volleyball tournament in the summer. The whole team committed to training for the tournament because there is a large cash prize for the top three teams. Keegan realizes what a big deal the tournament is so he goes to the gym and often practices his volleyball skills. However, Keegan is shorter than his friends and does not have much natural athletic talent. Despite his best effort, Keegan's poor volleyball skills cost his team the cash prize.

1) Following this experience, to what extent is Keegan feeling each of the following emotions:

\begin{tabular}{|c|c|c|c|c|c|}
\hline & 1 & 2 & 3 & 4 & 5 \\
\hline & Not at all & A little & Somewhat & Quite a bit & Very much so \\
\hline Shame & & & & & \\
\hline Anxiety & & & & & \\
\hline Guilt & & & & & \\
\hline Sadness & & & & & \\
\hline
\end{tabular}

OR

1) Following this experience, which of the following emotions do you think best describes how Keegan will feel? (select one of the four response options)
a. Anxiety
b. Shame
c. Guilt
d. Sadness

2) Following this experience, to what extent will Keegan desire forgiveness from himself?

\begin{tabular}{|c|c|c|c|c|}
\hline 1 & 2 & 3 & 4 & 5 \\
\hline Not at all & A little & Somewhat & Quite a bit & Very much so \\
\hline
\end{tabular}

3) Following this experience, to what extent will Keegan desire forgiveness from his friends?

\begin{tabular}{|c|c|c|c|c|}
\hline 1 & 2 & 3 & 4 & 5 \\
\hline Not at all & A little & Somewhat & Quite a bit & Very much so \\
\hline
\end{tabular}


Blake has never had much natural talent (i.e., been smart) in English. Blake recently had an important English exam and she studied hard for it but it still seemed very difficult for her. Even though Blake had done everything she could to prepare, she just found out she did badly on the exam, much worse than others in the class.

1) Following this experience, to what extent is Blake feeling each of the following emotions:

\begin{tabular}{|c|c|c|c|c|c|}
\hline & 1 & 2 & 3 & 4 & 5 \\
\hline Shame & Not at all & A little & Somewhat & Quite a bit & Very much so \\
\hline Anxiety & & & & \\
\hline Guilt & & & & \\
\hline Sadness & & & & \\
\hline
\end{tabular}

OR

1) Following this experience, which of the following emotions do you think best describes how Blake will feel? (select one of the four response options)
a. Guilt
b. Sadness
c. Anxiety
d. Shame

2) Following this experience, to what extent will Blake desire forgiveness from herself?

\begin{tabular}{|c|c|c|c|c|}
\hline 1 & 2 & 3 & 4 & 5 \\
\hline Not at all & A little & Somewhat & Quite a bit & Very much so \\
\hline
\end{tabular}


Rory has a group project in his Biology class. Although Rory knows that the project is a big part of his final grade and that his team members are counting on him, the night before it is due Rory chooses to go to a party. He ends up getting drunk and is unable to finish his part of the assignment. Since Rory's part of the assignment was incomplete, the team received a poor grade.

1) Following this experience, to what extent is Rory feeling each of the following emotions:

\begin{tabular}{|c|c|c|c|c|c|}
\hline & 1 & 2 & 3 & 4 & 5 \\
\hline Shame & Not at all & A little & Somewhat & Quite a bit & Very much so \\
\hline Anxiety & & & & & \\
\hline Guilt & & & & & \\
\hline Sadness & & & & & \\
\hline
\end{tabular}

OR

1) Following this experience, which of the following emotions do you think best describes how Rory will feel? (select one of the four response options)
a. Sadness
b. Anxiety
c. Shame
d. Guilt

2) Following this experience, to what extent will Rory desire forgiveness from himself?

\begin{tabular}{|c|c|c|c|c|}
\hline 1 & 2 & 3 & 4 & 5 \\
\hline Not at all & A little & Somewhat & Quite a bit & Very much so \\
\hline
\end{tabular}

3) Following this experience, to what extent will Rory desire forgiveness from his team members?

\begin{tabular}{|c|c|c|c|c|}
\hline 1 & 2 & 3 & 4 & 5 \\
\hline Not at all & A little & Somewhat & Quite a bit & Very much so \\
\hline
\end{tabular}


Jordan recently started watching a new show on Netflix that she really enjoyed. She has an important test coming up but she chooses to finish the Netflix series instead of study. On the day of the test she realized that she was not prepared. Jordan was so nervous that she would fail the test that she decided to cheat by looking at her notes. Jordan got caught for cheating and received a failing grade in the class as a result.

1) Following this experience, to what extent is Jordan feeling each of the following emotions:

\begin{tabular}{|c|c|c|c|c|c|}
\hline & 1 & 2 & 3 & 4 & 5 \\
\cline { 2 - 6 } & Not at all & A little & Somewhat & Quite a bit & Very much so \\
\hline Shame & & & & & \\
\hline Anxiety & & & & & \\
\hline Guilt & & & & & \\
\hline Sadness & & & & & \\
\hline
\end{tabular}

OR

1) Following this experience, which of the following emotions do you think best describes how Jordan will feel? (select one of the four response options)
a. Guilt
b. Sadness
c. Shame
d. Anxiety

2) Following this experience, to what extent will Jordan desire forgiveness from herself?

\begin{tabular}{|c|c|c|c|}
\hline 1 & 2 & 3 & 4 \\
\hline Not at all & A little & Somewhat & 5 \\
\hline
\end{tabular}


Ryan's best friend, Casey, was turning 20 and was coming from out of town to celebrate his birthday with Ryan. They had planned to go for dinner at Casey's favourite restaurant and then to a hockey game to watch his favourite team. On the morning that Casey arrived, Ryan slipped on ice and broke his arm. He needed to go to the hospital to get surgery and was no longer able to celebrate Casey's birthday with him.

1) Following this experience, to what extent is Casey feeling each of the following emotions:

\begin{tabular}{|c|c|c|c|c|c|}
\hline & 1 & 2 & 3 & 4 & 5 \\
\cline { 2 - 6 } & Not at all & A little & Somewhat & Quite a bit & Very much so \\
\hline Shame & & & & & \\
\hline Anxiety & & & & & \\
\hline Guilt & & & & & \\
\hline Sadness & & & & & \\
\hline
\end{tabular}

OR

1) Following this experience, which of the following emotions do you think best describes how Casey will feel? (select one of the four response options)
a. Anxiety
b. Guilt
c. Shame
d. Sadness

2) Following this experience, to what extent will Ryan desire forgiveness from himself?

\begin{tabular}{|c|c|c|c|c|}
\hline 1 & 2 & 3 & 4 & 5 \\
\hline Not at all & A little & Somewhat & Quite a bit & Very much so \\
\hline
\end{tabular}

3) Following this experience, to what extent will Ryan desire forgiveness from Casey?

\begin{tabular}{|c|c|c|c|c|}
\hline 1 & 2 & 3 & 4 & 5 \\
\hline Not at all & A little & Somewhat & Quite a bit & Very much so \\
\hline
\end{tabular}


Sawyer had been feeling quite sick for a few days and needed to go to the doctor to get medication. She decided to drive to the doctor's office to get the medication. On her drive to the doctor's office, Sawyer suddenly felt very dizzy and crashed her car into a street lamp on the side of the road and damaged her car.

1) Following this experience, to what extent is Sawyer feeling each of the following emotions:

\begin{tabular}{|c|c|c|c|c|c|}
\hline & 1 & 2 & 3 & 4 & 5 \\
\cline { 2 - 5 } & Not at all & A little & Somewhat & Quite a bit & Very much so \\
\hline Shame & & & & & \\
\hline Anxiety & & & & \\
\hline Guilt & & & & \\
\hline Sadness & & & & \\
\hline
\end{tabular}

OR

1) Following this experience, which of the following emotions do you think best describes how Sawyer will feel? (select one of the four response options)
a. Shame
b. Sadness
c. Anxiety
d. Guilt

2) Following this experience, to what extent will Sawyer desire forgiveness from herself?

\begin{tabular}{|c|c|c|c|c|}
\hline 1 & 2 & 3 & 4 & 5 \\
\hline Not at all & A little & Somewhat & Quite a bit & Very much so \\
\hline
\end{tabular}


Interpersonal Reactivity Index (IRI) (Davis, 1980).

\begin{tabular}{|c|c|c|c|c|}
\hline $\mathbf{0}$ & $\mathbf{1}$ & $\mathbf{2}$ & $\mathbf{3}$ & $\mathbf{4}$ \\
\hline $\begin{array}{c}\text { Does not } \\
\text { describe me well }\end{array}$ & & & & $\begin{array}{c}\text { Describes me very } \\
\text { well }\end{array}$ \\
\hline
\end{tabular}

1. I sometimes find it difficult to see things from the "other person's" point of view.

2. I try to look at everybody's side of a disagreement before I make a decision.

3. I sometimes try to understand my friends better by imagining how things look from their perspective.

4. If I'm sure I'm right about something, I don't waste much time listening to other people's arguments.

5. I believe that there are two sides to every question and try to look at them both.

6. When I'm upset at someone, I usually try to "put myself in his or her shoes" for a while.

7. Before criticizing somebody, I try to imagine how I would feel if I were in their place. 


\section{[Accuracy and Honesty Question]}

Sometimes, for a variety of reasons, people do not respond to study questions honestly or accurately. We recognize that this may occur, and it is very helpful to us in understanding our results if we can identify such cases. Please help us by answering the question below about how you responded to the questionnaire. You still receive full credit for participation in this study regardless of your response.

- Have you responded to this questionnaire package accurately and honestly?
Yes
Mostly
No 


\section{Appendix D \\ Debriefing}

Study Title: Responses Following Transgressions

Thank you for completing this study!

What are we trying to learn in this research?

The main purpose of this study is to better understand the ways in which people understand and try to make sense of a perpetrator's emotional and behavioural response after committing a transgression. Prior studies indicate that the reasons people believe caused an event to happen influences the emotions that people experience and that these emotions influence how people act. In this research, we are specifically exploring whether people believe that a) beliefs about why an event happened influences emotions and b) distinct emotions influence the likelihood of desiring forgiveness from the self and others. You were assigned to one of two response conditions. You either responded using forced choice or a continuous scale when asked about the emotions of the actors in the scenarios. This was done in order to identify whether people tend to view shame and guilt as distinct emotions.

\section{Why is this important to scientists or to the general public?}

Transgressions are inevitable and the experience of harming others is as universal as being harmed. This research will allow us to better understand how people make sense of a perpetrator's experience following transgressions. Ultimately, this and subsequent research may contribute to the development of conflict resolution strategies.

Where can I learn more?

For more information about shame and guilt and the distinction between the two emotions, see https://www.psychologytoday.com/ca/blog/shame/201305/the-difference-between-guilt-andshame

\section{Contact Information:}

For additional questions or comments, please contact Elisabeth Bailin Xie (elisabethxie@cmail.carleton.ca) or Dr. Chris Davis (chris.davis@carleton.ca)

In case of ethical concerns about this study, please contact Dr. Natasha Artemeva, Chair of the Carleton University Research Ethics Board - B (1 613-520-2600x4085; ethics@carleton.ca)

This study has received clearance by the Carleton University Research Ethics Board -B (CUREB- B \#110758, expiry: June 30, 2020)

Thank you for your participation!

To ensure maximum confidentiality, please exit this browser by clicking 'Next' at the bottom of this page. 


\section{Study 2 Appendices}

\section{Appendix A}

Recruitment Notice:

Responses Following Transgressions

(10 min or less $/ .25 \%$ course credit)

Have you ever thought about how people feel or react after making a mistake? Almost everyone will at some point find themselves in the wrong or be disappointed with an outcome. We won't ask you to think about your own experiences, but we would love to ask you some questions about how you think people respond to negative outcomes.

You will be asked to read a series of scenarios about wrongdoings committed by others and answer a few questions regarding the feelings and future behaviours of these individuals. We will also ask you a few questions about your own personality. Your participation is completely anonymous. The questionnaire will take approximately 10 minutes to complete. You will receive $.25 \%$ credit in compensation for your time.

Your contribution to this research is greatly appreciated!!

This study has received clearance by the Carleton University Research Ethics Board -B (CUREB-B \#110758, expiry: June 30, 2020).

If you have any questions or concerns regarding this study, please contact Elisabeth Xie at elisabethxie@,cmail.carleton.ca or the faculty supervisor Dr. Chris Davis at chris.davis@carleton.ca . 


\section{Appendix B \\ Informed Consent:}

The purpose of an informed consent is to ensure that you understand the purpose of the study and the nature of your involvement. The informed consent is intended to provide sufficient information, such that you have the opportunity to determine whether you wish to participate in the study. This study has received clearance by the Carleton University Research Ethics Board $B$ (CUREB-B \#110758, expiry: June 30, 2020).

Study Title: Responses Following Transgressions

Study Personnel Contact: The Principal Investigators of this project are Elisabeth Xie (elisabethxie@.cmail.carleton.ca) and Dr. Chris Davis (Faculty, chris.davis@carleton.ca) from the Psychology Department at Carleton University.

Contact in case of concerns: Should you have any ethical concerns about this study then please contact Dr. Natasha Artemeva, Chair of the Carleton University Research Ethics Board-B (613520-2600x4085; ethics@carleton.ca).

Purpose and Task Requirements: The purpose of this study is to gain a better understanding of the way in which people understand and make sense of a perpetrator's experience (i.e., emotions and behavioural responses) after committing a transgression. You will be asked to read a series of scenarios about other people who have acted in ways that are potentially harmful for the self or others and answer a few questions about your opinion on their emotions. This study will take approximately 10 minutes to complete.

Compensation: You will receive a .25\% course credit for your participation.

Anonymity/Confidentiality: The data collected in this study are anonymous. All data are coded so that your name cannot be associated with any responses that you have provided. Any identifying information associated with your code will be removed from your data once your course credit has been granted. Once the data are anonymous, aggregated data might be shared with trusted colleagues. We collect data through the software Qualtrics, which uses servers with multiple layers of security to protect the privacy of the data (e.g., encrypted websites and password protected storage). The anonymous data will be kept by the primary researchers for 5 years after publication as per American Psychological Association requirements. With your consent to participate in this study you acknowledge this.

Right to Withdraw: Your participation in this study is entirely voluntary. At any point during the study you have the right to not complete any questions or to withdraw with no penalty. If you decide to withdraw from the study you will still receive full compensation for your participation. Withdrawing from the study prior to completion indicates that you do not wish to have your responses included, and data will be deleted if you skip to debriefing to withdraw from the study. Those who do complete the study consent to the use of their responses (in aggregate form) for research and teaching purposes. As responses are anonymous, we cannot remove your data from the study after you submit. 
If you would like to participate in this study, please click the Agree button below. Otherwise, click the Disagree button.

\section{Agree}

Disagree - exit to debriefing 


\section{Appendix C \\ Survey Materials}

Thank you for participating in our study! This study will take approximately 10 minutes to complete. Please read each question carefully.

\section{Demographic Questions}

First, we would like to gather some demographic information. All information you provide will be completely confidential and will not be associated in any way with your identity. Please answer the questions below.

1. What is your gender?

Female

Male

Other

2. What is your Age: (in years) 


\section{Scenarios}

You will be presented with four different scenarios. You will then be asked a question about their resulting emotion. Please carefully read and think about each of the following scenarios before answering each question.

Keegan registered for an English course. The final assignment for the course was a group presentation in front of the class. Keegan has always been terrified of public speaking and has never felt comfortable talking to strangers. However, Keegan does not want to let his group down. He spends as much time as possible practicing his part of the presentation so that he is ready for presentation day. Even though Keegan tried his best, on presentation day he was so nervous that he was unable to present his part of the project. As a result, his team looked unprepared and he just found out his whole team received a very poor grade.

2) Following this experience, to what extent is Keegan feeling each of the following emotions:

\begin{tabular}{|c|c|c|c|c|c|}
\hline & 1 & 2 & 3 & 4 & 5 \\
\hline & Not at all & A little & Somewhat & Quite a bit & Very much so \\
\hline Shame & & & & & \\
\hline Anxiety & & & & & \\
\hline Guilt & & & & & \\
\hline Anger & & & & & \\
\hline
\end{tabular}


Blake has never had much natural talent (i.e., been smart) in math. Even though she has always tried to improve, math has always been her worst subject. Blake has an important math exam coming up and she knows how important this grade will be for her GPA. Blake studies every day for it and also registers for tutoring but it still seems very difficult for her. Even though Blake did everything she could to prepare, she just found out she did very badly on the exam, much worse than others in the class.

2) Following this experience, to what extent is Blake feeling each of the following emotions:

\begin{tabular}{|c|c|c|c|c|c|}
\hline & 1 & 2 & 3 & 4 & 5 \\
\hline Shame & Not at all & A little & Somewhat & Quite a bit & Very much so \\
\hline Anxiety & & & & & \\
\hline Guilt & & & & & \\
\hline Anger & & & & \\
\hline
\end{tabular}


Rory has a group lab report due in his Biology class. Although Rory knows that this lab report is a big part of the final grade in the course and that her team members are counting on her, the night before it is due Rory chooses to go to a party. She chooses to stay out late and get drunk with her friends. As a result, she does not finish her part of the assignment. Rory just found out that because her part of the assignment was incomplete, the whole team received a very poor grade on the group assignment.

2) Following this experience, to what extent is Rory feeling each of the following emotions:

\begin{tabular}{|c|c|c|c|c|c|}
\hline & 1 & 2 & 3 & 4 & 5 \\
\hline & Not at all & A little & Somewhat & Quite a bit & Very much so \\
\hline Shame & & & & & \\
\hline Anxiety & & & & & \\
\hline Guilt & & & & & \\
\hline Anger & & & & & \\
\hline
\end{tabular}


Jordan recently started watching a new show on Netflix that he really enjoys. He knows he has a psychology test coming up but she chooses to finish the Netflix series instead of study. On the day of the test he realized that he had not studied at all and was not prepared. Because he chose not to study, Jordan was worried that he would fail the test. He decided to cheat during the test by looking at his notes. Jordan got caught for cheating and just found out that he received a failing grade in the course as a result.

3) Following this experience, to what extent is Jordan feeling each of the following emotions:

\begin{tabular}{|c|c|c|c|c|c|}
\hline & 1 & 2 & 3 & 4 & 5 \\
\cline { 2 - 5 } & Not at all & A little & Somewhat & Quite a bit & Very much so \\
\hline Shame & & & & & \\
\hline Anxiety & & & & & \\
\hline Guilt & & & & & \\
\hline Anger & & & & \\
\hline
\end{tabular}




\section{[Accuracy and Honesty Question]}

Sometimes, for a variety of reasons, people do not respond to study questions honestly or accurately. We recognize that this may occur, and it is very helpful to us in understanding our results if we can identify such cases. Please help us by answering the question below about how you responded to the questionnaire. You still receive full credit for participation in this study regardless of your response.

- Have you responded to this questionnaire package accurately and honestly?

Yes Mostly _ No 


\section{Appendix D \\ Debriefing}

Study Title: Responses Following Transgressions

Thank you for completing this study!

What are we trying to learn in this research?

The main purpose of this study is to better understand the ways in which people understand and try to make sense of a perpetrator's emotional and behavioural response after committing a transgression. Prior studies indicate that the reasons people believe caused an event to happen influences the emotions that people experience and that these emotions influence how people act. In this research, we are specifically exploring whether people believe that beliefs about why an event happened influences emotions.

Why is this important to scientists or to the general public?

Transgressions are inevitable and the experience of harming others is as universal as being harmed. This research will allow us to better understand how people make sense of a perpetrator's experience following transgressions. Ultimately, this and subsequent research may contribute to the development of conflict resolution strategies.

Where can I learn more?

For more information about shame and guilt and the distinction between the two emotions, see https://www.psychologytoday.com/ca/blog/shame/201305/the-difference-between-guilt-andshame

\section{Contact Information:}

For additional questions or comments, please contact Elisabeth Bailin Xie (elisabethxie@cmail.carleton.ca) or Dr. Chris Davis (chris.davis@carleton.ca)

In case of ethical concerns about this study, please contact Dr. Natasha Artemeva, Chair of the Carleton University Research Ethics Board - B (1 613-520-2600x4085; ethics@carleton.ca)

This study has received clearance by the Carleton University Research Ethics Board -B (CUREB- B \#110758, expiry: June 30, 2020)

Thank you for your participation!

To ensure maximum confidentiality, please exit this browser by clicking 'Next' at the bottom of this page. 


\title{
Study 3 Appendices
}

\author{
Appendix A \\ Recruitment Notice: \\ Responses Following Transgressions \\ (20 $\mathrm{min}$ or less $/ .25 \%$ course credit)
}

Have you ever thought about how people feel or react after a negative outcome? Almost everyone will at some point find themselves in the wrong or be disappointed with an outcome. We won't ask you to think about your own experiences, but we would love to ask you some questions about how you think people respond following transgressions they have committed.

You will be asked to read a series of scenarios about transgressions committed by others and answer a few questions regarding the feelings and future behaviours of these individuals. Your participation is completely anonymous. The questionnaire will take approximately 20 minutes to complete. You will receive $.25 \%$ credit in compensation for your time.

To be eligible for this study, you must be fluent in English.

Your contribution to this research is greatly appreciated!!

This study has received clearance by the Carleton University Research Ethics Board -B (CUREB- B \#110758, expiry: June 30, 2020).

If you have any questions or concerns regarding this study, please contact Elisabeth Xie at elisabethxie@cmail.carleton.ca or the faculty supervisor Dr. Chris Davis at chris.davis@carleton.ca . 


\section{Appendix B \\ Informed Consent:}

The purpose of an informed consent is to ensure that you understand the purpose of the study and the nature of your involvement. The informed consent is intended to provide sufficient information, such that you have the opportunity to determine whether you wish to participate in the study. This study has received clearance by the Carleton University Research Ethics Board $B$ (CUREB-B \#110758, expiry: June 30, 2020).

Study Title: Responses Following Transgressions

Study Personnel Contact: The Principal Investigators of this project are Elisabeth Xie (elisabethxie@cmail.carleton.ca) and Dr. Chris Davis (Faculty, chris.davis@carleton.ca) from the Psychology Department at Carleton University.

Contact in case of concerns: Should you have any ethical concerns about this study then please contact the Chair of the Carleton University Research Ethics Board-B (613-520-2600x4085; ethics@carleton.ca).

Purpose and Task Requirements: The purpose of this study is to gain a better understanding of the way in which people understand and make sense of a perpetrator's experience (i.e., emotions and behavioural responses) after committing a transgression. You will be asked to read a series of scenarios about other people who have acted in ways that are potentially harmful for the self or others and answer a few questions about your opinion on their emotions. This study will take approximately 20 minutes to complete.

Eligibility Requirements: Participants must be fluent in English.

Compensation: You will receive a $.25 \%$ course credit for your participation.

Anonymity/Confidentiality: The data collected in this study are anonymous. All data are coded so that your name cannot be associated with any responses that you have provided. Any identifying information associated with your code will be removed from your data once your course credit has been granted. Once the data are anonymous, aggregated data might be shared with trusted colleagues. We collect data through the software Qualtrics, which uses servers with multiple layers of security to protect the privacy of the data (e.g., encrypted websites and password protected storage). The anonymous data will be kept by the primary researchers for 5 years after publication as per American Psychological Association requirements. With your consent to participate in this study you acknowledge this.

Right to Withdraw: Your participation in this study is entirely voluntary. At any point during the study you have the right to not complete any questions or to withdraw with no penalty. If you decide to withdraw from the study you will still receive full compensation for your participation. Withdrawing from the study prior to completion indicates that you do not wish to have your responses included, and data will be deleted if you skip to debriefing to withdraw from the study. Those who do complete the study consent to the use of their responses (in aggregate form) for 
research and teaching purposes. As responses are anonymous, we cannot remove your data from the study after you submit.

If you would like to participate in this study, please click the Agree button below. Otherwise, click the Disagree button.

\author{
Agree \\ Disagree - exit to debriefing
}




\section{Appendix C \\ Survey Materials}

Thank you for participating in our study! This study will take approximately 20 minutes to complete. Please read each question carefully.

\section{Demographic Questions}

First, we would like to gather some demographic information. All information you provide will be completely confidential and will not be associated in any way with your identity. Please answer the questions below.

1. What is your gender?

Female

Male

Other

2. What is your Age: (in years)

To what extent do you understand and read the English language?

\begin{tabular}{|c|c|c|}
\hline 1 & 2 & 3 \\
\hline $\begin{array}{c}\text { Not very } \\
\text { well }\end{array}$ & Somewhat & Quite well \\
\hline
\end{tabular}




\section{Scenarios}

You will be presented with four different scenarios. You will then be asked questions about how each actor feels as a result of the scenario. Please carefully read and think about each of the following scenarios before answering each question. 
Keegan owns a car. Keegan was driving with three friends in the passenger seats. Keegan knows it is important to stay focused on the road and tries hard to do so. However, Keegan has always had a hard time paying attention while driving and has had many minor car accidents as a result. Recently, Keegan was distracted and lost control of the car. The car smashed into a lamp post on the side of the road. Keegan's car was damaged and Keegan and the three friends in the car suffered injuries. No other cars were involved in the accident.

3) Following this experience, to what extent is Keegan likely to feel each of the following:

\begin{tabular}{|c|c|c|c|c|c|}
\hline & 1 & 2 & 3 & 4 & 5 \\
\hline & $\begin{array}{l}\text { Not at } \\
\text { all }\end{array}$ & A little & Somewhat & Quite a bit & $\begin{array}{l}\text { Very } \\
\text { much so }\end{array}$ \\
\hline Feel shame & & & & & \\
\hline Feel remorse and regret & & & & & \\
\hline Feel guilt & & & & & \\
\hline Feel like a bad person & & & & & \\
\hline Feel humiliated and disgraced & & & & & \\
\hline $\begin{array}{l}\text { Feel bad about something he or } \\
\text { she did }\end{array}$ & & & & & \\
\hline
\end{tabular}

4) Following this experience, to what extent will Keegan desire forgiveness from the friends that were in the car?

\begin{tabular}{|c|c|c|c|c|}
\hline 1 & 2 & 3 & 4 & 5 \\
\hline Not at all & A little & Somewhat & Quite a bit & Very much so \\
\hline
\end{tabular}

5) Following this experience, to what extent will Keegan desire forgiveness from himself/herself?

\begin{tabular}{|c|c|c|c|c|}
\hline 1 & 2 & 3 & 4 & 5 \\
\hline $\begin{array}{c}\text { Not at all } \\
\text { (skip } \\
\text { question 4) }\end{array}$ & A little & Somewhat & Quite a bit & Very much so \\
\hline
\end{tabular}

6) To what extent will Keegan forgive himself/herself?

\begin{tabular}{|c|c|c|c|}
\hline 1 & 2 & 3 & 4 \\
Not at all & A little & Somewhat & 5 \\
\hline
\end{tabular}


Blake owns a car. Blake was driving alone. Blake knows it is important to stay focused on the road and tries hard to do so. However, Blake has always had a hard time paying attention while driving and has had many minor car accidents as a result. Recently, Blake was distracted and lost control of the car. The car smashed into a lamp post on the side of the road. Blake's car was damaged and Blake suffered injuries. No other cars were involved in the accident.

3) Following this experience, to what extent is Blake likely to feel each of the following:

\begin{tabular}{|c|c|c|c|c|}
\hline & $\begin{array}{c}1 \\
\text { Fot at all }\end{array}$ & A little & 3 & 4 \\
\hline Feel shame & Somewhat & Quite a bit & $\begin{array}{c}\text { Very } \\
\text { much so }\end{array}$ \\
\hline $\begin{array}{c}\text { Feel like a bad person } \\
\text { Feel humiliated and } \\
\text { disgraced }\end{array}$ & & & & \\
\hline $\begin{array}{c}\text { Feel bad about } \\
\text { something he or she did }\end{array}$
\end{tabular}

4) Following this experience, to what extent will Blake desire forgiveness from the self?

\begin{tabular}{|c|c|c|c|}
\hline 1 & 2 & 3 & 4 \\
\hline $\begin{array}{c}\text { Not at all } \\
\text { (skip } \\
\text { question 3) }\end{array}$ & A little & Somewhat & Quite a bit
\end{tabular}

5) To what extent will Blake forgive the himself/herself?

\begin{tabular}{|c|c|c|c|c|}
\hline 1 & 2 & 3 & 4 & 5 \\
\hline Not at all & A little & Somewhat & Quite a bit & Very much so \\
\hline
\end{tabular}


Rory owns a car. Rory was driving with three friends in the passenger seats. Rory knows that texting and driving is illegal and usually tries not to look at text messages while driving. However, while driving, Rory received a text message and Rory decided to answer this text while still driving. Texting and driving caused Rory to lose control of the car and the car smashed into a lamp post on the side of the road. Rory's car was damaged and everyone in the car suffered injuries. No other cars were involved in the accident.

3) Following this experience, to what extent is Rory likely to feel each of the following:

\begin{tabular}{|c|c|c|c|c|c|}
\hline & 1 & 2 & 4 & 5 \\
\hline & Not at all & A little & Somewhat & Quite a bit & Very much so \\
\hline $\begin{array}{c}\text { Feel shame } \\
\text { Feel remorse } \\
\text { and regret }\end{array}$ & & & & \\
\hline $\begin{array}{c}\text { Feel guilt } \\
\text { Feel like a } \\
\text { bad person }\end{array}$ & & & & \\
\hline $\begin{array}{c}\text { Feel } \\
\text { humiliated } \\
\text { and disgraced }\end{array}$ & & & \\
\hline $\begin{array}{c}\text { Feel bad } \\
\text { about } \\
\text { something he } \\
\text { or she did }\end{array}$ & & & \\
\hline
\end{tabular}

4) Following this experience, to what extent will Rory desire forgiveness from the friends that were in the car?

\begin{tabular}{|c|c|c|c|}
\hline 1 & 2 & 3 & 4 \\
Not at all & A little & Somewhat & 5 \\
\hline
\end{tabular}

5) Following this experience, to what extent will Rory desire forgiveness from himself/herself?

\begin{tabular}{|c|c|c|c|c|}
\hline 1 & 2 & 3 & 4 & 5 \\
\hline $\begin{array}{c}\text { Not at all } \\
\text { (skip } \\
\text { question 4) }\end{array}$ & A little & Somewhat & Quite a bit & Very much so \\
\hline
\end{tabular}

6) To what extent will Rory forgive himself/herself?

\begin{tabular}{|c|c|c|c|c|}
\hline 1 & 2 & 3 & 4 & 5 \\
\hline Not at all & A little & Somewhat & Quite a bit & Very much so \\
\hline
\end{tabular}


Jordan owns a car. Jordan was driving alone. Jordan knows that texting and driving is illegal and usually tries not to look at text messages while driving. However, while driving, Jordan received a text message and Jordan decided to answer this text while still driving. Texting and driving caused Jordan to lose control of the car and the car smashed into a lamp post on the side of the road. Jordan's car was damaged and Jordan suffered injuries. No other cars were involved in the accident.

4) Following this experience, to what extent is Jordan likely to feel each of the following:

$\left.\begin{array}{|c|c|c|c|c|c|}\hline & 1 & 2 & 4 & 5 \\ \hline \begin{array}{c}\text { Feel shame } \\ \text { Feel remorse } \\ \text { and regret }\end{array} & \text { Not at all } & \text { A little } & \text { Somewhat } & \text { Quite a bit } & \text { Very much so } \\ \hline \begin{array}{c}\text { Feel guilt } \\ \text { Feel like a } \\ \text { bad person }\end{array} & & & & \\ \hline \begin{array}{c}\text { Feel } \\ \text { humiliated } \\ \text { and disgraced }\end{array}\end{array}\right]$

5) Following this experience, to what extent will Jordan desire forgiveness from himself/herself?

\begin{tabular}{|c|c|c|c|c|}
\hline 1 & 2 & 3 & 4 & 5 \\
\hline $\begin{array}{l}\text { Not at all } \\
\text { (skip } \\
\text { question 3) }\end{array}$ & A little & Somewhat & Quite a bit & Very much so \\
\hline
\end{tabular}

6) To what extent will Jordan forgive himself/herself?

\begin{tabular}{|c|c|c|c|c|}
\hline 1 & 2 & 3 & 4 & 5 \\
\hline Not at all & A little & Somewhat & Quite a bit & Very much so \\
\hline
\end{tabular}




\section{[Accuracy and Honesty Question]}

Sometimes, for a variety of reasons, people do not respond to study questions honestly or accurately. We recognize that this may occur, and it is very helpful to us in understanding our results if we can identify such cases. Please help us by answering the question below about how you responded to the questionnaire. You still receive full credit for participation in this study regardless of your response.

- Have you responded to this questionnaire package accurately and honestly?

Yes _ Mostly _ No




\section{Appendix D \\ Debriefing}

Study Title: Responses Following Transgressions

Thank you for completing this study!

What are we trying to learn in this research?

The main purpose of this study is to better understand the ways in which people understand and try to make sense of a perpetrator's emotional and behavioural response after committing a transgression. Prior studies indicate that the reasons people believe caused an event to happen influences the emotions that people experience and that these emotions influence how people act. In this research, we are specifically exploring whether people believe that beliefs about why an event happened influences emotions. We are also exploring whether perceptions of emotions influence the extent to which people believe others will seek forgiveness and forgive themselves for a transgression.

Why is this important to scientists or to the general public?

Transgressions are inevitable and the experience of harming others is as universal as being harmed. This research will allow us to better understand how people make sense of a perpetrator's experience following transgressions. Ultimately, this and subsequent research may contribute to the development of conflict resolution strategies.

\section{Where can I learn more?}

For more information about shame and guilt and the distinction between the two emotions, see https://www.psychologytoday.com/ca/blog/shame/201305/the-difference-between-guilt-andshame

\section{Contact Information:}

For additional questions or comments, please contact Elisabeth Bailin Xie (elisabethxie@cmail.carleton.ca) or Dr. Chris Davis (chris.davis@carleton.ca)

In case of ethical concerns about this study, please contact the Chair of the Carleton University Research Ethics Board - B (1 613-520-2600x4085; ethics@carleton.ca)

This study has received clearance by the Carleton University Research Ethics Board -B (CUREB- B \#110758, expiry: June 30, 2020)

Thank you for your participation!

To ensure maximum confidentiality, please exit this browser by clicking 'Next' at the bottom of this page. 